\title{
EXPERIMENTAL TESTING OF JOINTS FOR SEISMIC DESIGN OF LIGHTWEIGHT STRUCTURES. PART 3: GUSSETS, CORNER JOINTS AND X-BRACED FRAMES
}

\author{
Miquel Casafont ${ }^{\mathrm{a}}$, Alfredo Arnedo ${ }^{\mathrm{b}}$, Francesc Roure $^{\mathrm{a}}$, and \\ Antonio Rodríguez-Ferran ${ }^{\mathrm{c} \dagger}$ \\ a Departament de Resistència de Materials i Estructures a l'Enginyeria, \\ E.T.S. d'Enginyeria Industrial de Barcelona, \\ Universitat Politècnica de Catalunya, Av. Diagonal 647, 08028, Barcelona, Spain \\ ${ }^{b}$ Departament d'Enginyeria de la Construcció, \\ E.T.S. d'Enginyers de Camins, Canals i Ports de Barcelona, \\ Universitat Politècnica de Catalunya, Jordi Girona 1, 08034, Barcelona, Spain \\ SENER, Ingeniería y Sistemas, S.A.
${ }^{\mathrm{C}}$ Laboratori de Càlcul Numèric (LaCàN), Departament de Matemàtica Aplicada III, E.T.S. d'Enginyers de Camins, Canals i Ports de Barcelona, Universitat Politècnica de Catalunya, Jordi Girona 1, 08034, Barcelona, Spain

\begin{abstract}
An experimental campaign on joints of $x$-braced frames is presented. Tests are performed on strap-gusset joints and lower and upper corner joints. Many different phenomena and failure modes are observed in these tests. However, it is possible to see that only one failure mode can be accepted if a good seismic performance of the frame needs to be guaranteed: the net section failure of the diagonal strap after yielding. The results of the tests also allow to establish a set of recommendations for seismic design of joints. The effectiveness of these recommendations is verified by means of two final tests on complete $x$-braced frames. A full explanation on the behaviour of the joints and frames tested is included, together with a description of the special test setup developed for the experimental campaign.
\end{abstract}

\section{Keywords:}

Light gauge steel; lightweight steel; seismic design; joints; bolts; experimental research; ductility; failure modes; x-bracing; shear wall.

\section{Introduction}

Shear walls with x-bracings and/or suitable cladding are commonly used in lightweight structures to support the horizontal loads caused by earthquakes.

\footnotetext{
* Research supported by the Research Fund for Coal and Steel (grant 7210-PR-377) and the "Ministerio de Educación y Ciencia" (grant DPI2002-12388-E)

† Corresponding author. Tel.: +34 934015697 Fax: +34 934011825

e-mail: antonio.rodriguez-ferran@upc.edu

URL: http://www-lacan.upc.edu
} 
Their performance depends on the behaviour of their three main parts: members, bracing system and joints.

The present investigation is focused on joints, which play a crucial role in seismic design because they govern parameters such as the strength, the stiffness and the dissipative behaviour of shear frames. For instance, when sandwich panels are used as cladding, connections panel to panel and panel to frame are a source of energy dissipation and, at the same time, they also determine whether the dissipative action of the panels can occur [1].

In a similar way, when x-bracings are used, connections should be designed so that they are strong enough to allow the development of the dissipative action of the bracings, i.e., the strength of connections should be higher than the yielding load of diagonal straps. For the same reason, the strength of the members of the frame has also to be higher than this yielding load [2]. This problem related to the strength of the members is also considered in the present paper, but it is not the main topic.

The investigation is performed in the context of the European research project "Seismic Design of Light-Gauge Steel Framed Buildings". Generally speaking, the experimental campaign has two main objectives: the first one is to gain knowledge about the behaviour of joints, in order to establish criteria for their seismic design; and the second one is to obtain experimental data to calibrate a numerical model also developed in the project [3].

The first tests of the experimental campaign are performed on strap-strap joints. Tests of this type have been widely carried out in many other investigations, some of which are focused on the subject of connection ductility or seismic design of joints. In this sense, the tests performed by De Matteis and Landolfo $[1,4]$ and Füllöp and Dubina $[5,6]$ for the investigation of the seismic behaviour of shear frames with cladding can be mentioned.

The results of the strap-strap tests carried out in the present investigation are reported in two previous papers $[7,8]$. These results allowed for the determination of a set of basic recommendations for joint design.

On the other hand, literature on tests performed on complete shear frames also gives information about the convenient design of joints. Failure of joints together with buckling of members are the two main causes of frame collapse reported in papers [5,9-12]. It is also possible to see that corner joints are the main focus of structural damage, and that, for example, the uplift phenomenon and the excessive deformation of corner connections can significantly reduce the dissipative capacity of frames $[5,10]$.

Actually, the aim of this paper is to present the results of a set of new tests on xbraced frames. These tests are performed on parts of the frames: strap-gusset joints and lower and upper corner joints. It is expected that the results of the tests will allow to verify and complete the design recommendations that were previously defined from the results of the strap-strap joints. 
In the last phase of the experimental campaign, verification tests are performed on two identical full $x$-braced frames, which are designed according to the mentioned design recommendations. In view of the results obtained, it will be possible to check whether these recommendations are really effective.

In relation to the second main objective, it should be pointed out that it is necessary to know the behaviour of joints to develop numerical models for the simulation of frames subjected to seismic loads [13-15]. This is why a description of the joint behaviour observed in the experimental campaign is included in the present paper. Special attention is paid to the forcedisplacement curves, from which parameters such as the initial and the tangent stiffness of connections are obtained.

In a second stage, the experimental tests on the complete $x$-braced shear frames are used to verify and improve the accuracy of the proposed numerical model. For this reason, an extensive explanation on the experimental behaviour of the frame will also be given. This may be very helpful for the understanding of the features finally adopted for the model developed. The description of this model is not included in the present paper, it can be found in [3].

An outline of the paper follows. The results of the first phase of the investigation, focused on strap-strap joints, are summarized in section 2 . The following three sections present the new tests on gusset-strap joints and lower and upper corner joints. They include an explanation on the special equipment needed for the tests, a description of the joint behaviour and the lessons learned from the experimental results related to the seismic design of connections. Subsequently, section 6 describes the verification tests performed on $x$-braced shear frames. The recommendations for design and the concluding remarks given in section 7 close the paper.

\section{Tests on joints between straps}

\subsection{Screwed joints between straps}

The results of the tests performed on screwed strap-strap connections (Fig. 1) allowed to distinguish two types of joint behaviour. On the one hand, there are joints whose failure mode is basically a combination of tilting and net section failure (the T+NSF joints, Fig. 2 and 3). On the other hand, there is a second group of joints that fail in a combination of tilting, bearing and pull out or, sometimes, pull through (the $\mathrm{T}+\mathrm{B}+\mathrm{PO}$ joints, Fig. 4 and 5 ).

From the seismic point of view, the distinction between these two groups is very important because, as it was demonstrated in [7], only $T+N S F$ joints are suitable for dissipative $x$-bracings of lightweight structures. The main problem with the $\mathrm{T}+\mathrm{B}+\mathrm{PO}$ type of joints is that their failure occurs before the yielding of the diagonal straps and, as a consequence, no dissipation can be developed (see in Fig. 5 the load level $A_{g t} \cdot f_{y t}$ corresponding to the yielding load of the strap). On the contrary, T+NSF joints have enough strength to allow the cyclic 


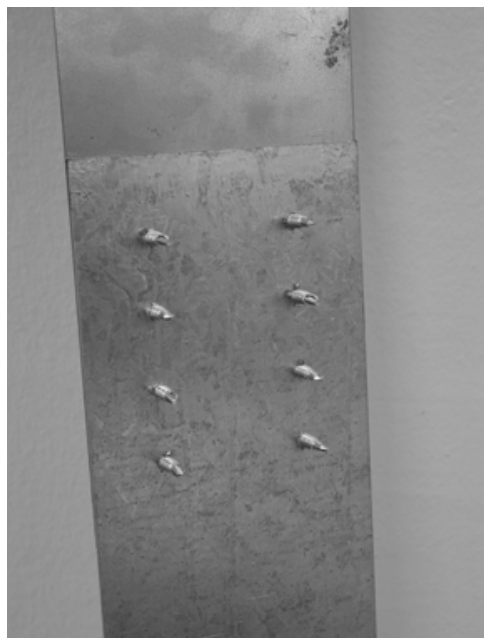

Fig. 1. Screwed joint.

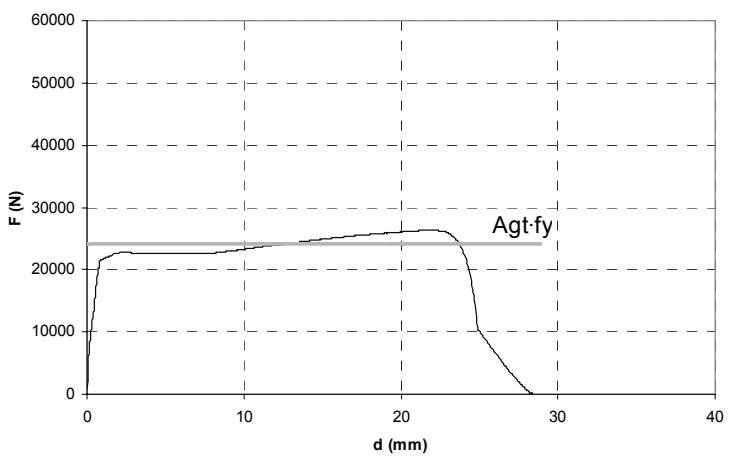

Fig. 3. F-d curve of a $T+N S F$ joint.

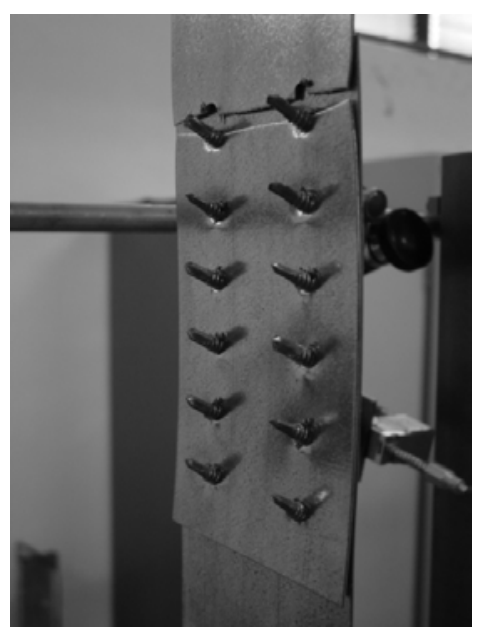

Fig. 2. $T+N S F$ failure.

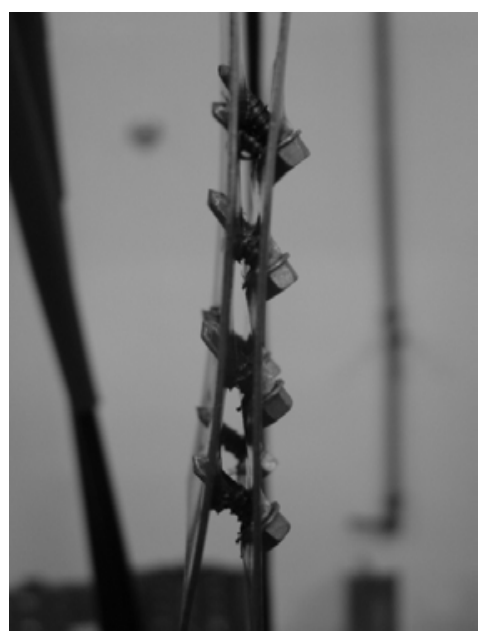

Fig. 4. $T+B+P O$ failure.

yielding of the diagonals. There can be dissipative action, which takes place in the load interval between the yielding load of the strap gross cross-section and the ultimate load of the joint (Fig. 3).

Moreover, when the ductility of the joint itself is investigated, it is observed that the $\mathrm{T}+\mathrm{NSF}$ failure is rather more ductile than the $\mathrm{T}+\mathrm{B}+\mathrm{PO}$ failure. This also makes the T+NSF joints more suitable for structures subjected to seismic loads.

In view of the results obtained, it was recommended in [7] to design x-braced shear walls with screw connections failing in the NSF mode.

\section{2 Bolted joints between straps}

The results of the investigation on bolted joints (Fig. 6) are similar, in some senses, to the results obtained in the tests on screwed connections. For instance, two modes of failure are also observed: a combination of tilting, bearing and sheet tearing ( $\mathrm{T}+\mathrm{B}+\mathrm{TS}$, Figs. 7 and 8$)$; and a combination of tilting, bearing and net section failure of the strap ( $T+B+N S F$, Fig. 9). Both 


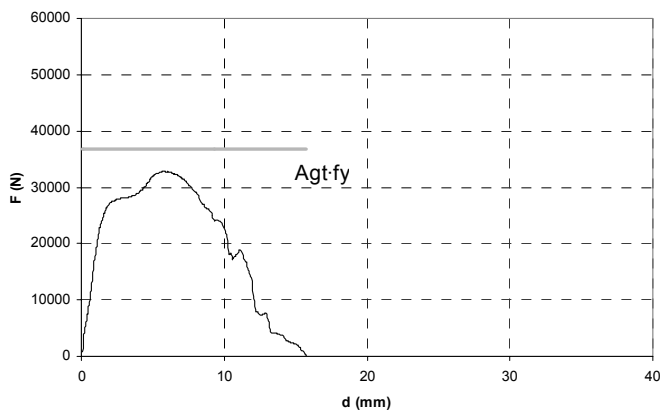

Fig. 5. F-d curve of a $T+B+P O$ joint.

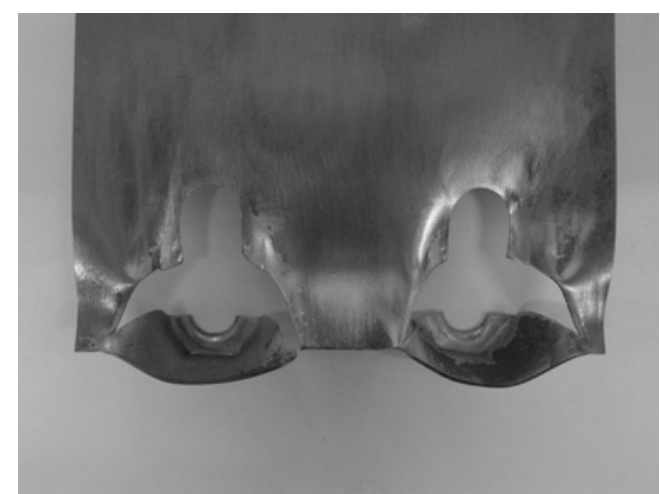

Fig. 7. $T+B+T S$ failure (tears initiated at the edge of the bearing zones).

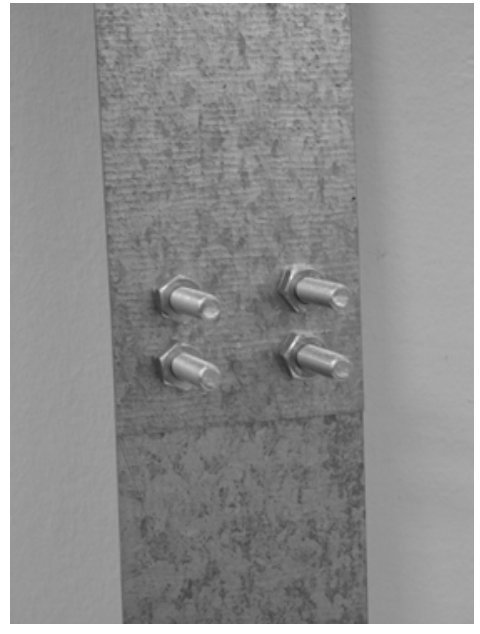

Fig. 6. Bolted joint.

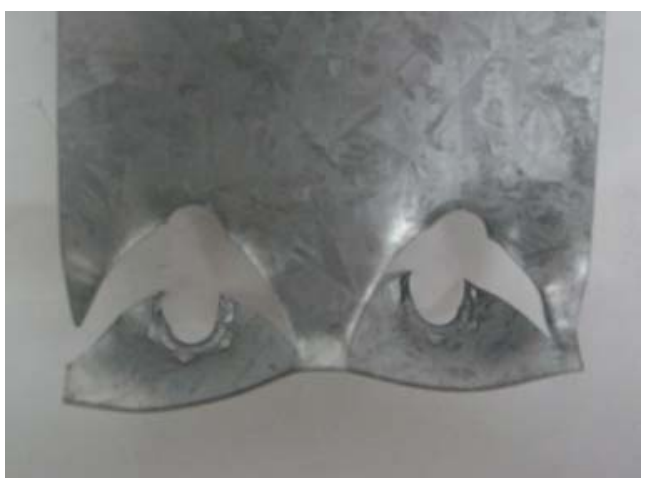

Fig. 8. $T+B+T S$ failure (tears initiated near the centre of the bolt holes).

modes are ductile, their ductility ratios range between medium to high values (see [8]), but the ductility of the joints that undergo the net-section failure $(\mathrm{T}+\mathrm{B}+\mathrm{NSF})$ is higher than the ductility of the joints that fail bearing $(\mathrm{T}+\mathrm{B}+\mathrm{TS})$. Therefore, regarding the ductility of the joint itself, the NSF type of joint is again preferred.

The most important difference with screw joints is that none of the mentioned types of bolted joints are suitable for seismic design. When the failure is $\mathrm{T}+\mathrm{B}+\mathrm{TS}$, the strength of the connection is usually far lower than the yielding load of the strap (See Fig. 10). When the failure mode is $T+B+N S F$, the ultimate load is closer to this yielding load, but most of the times below it (Fig. 11).

Therefore, the main conclusion that resulted from this investigation is that it is not recommended to use bolts in connections of dissipative x-braced frames.

It should be pointed out, however, that the behaviour of bolted connections may slightly improve if some design precautions are taken, for example if washers are used (see Fig. 12 and [8]). 


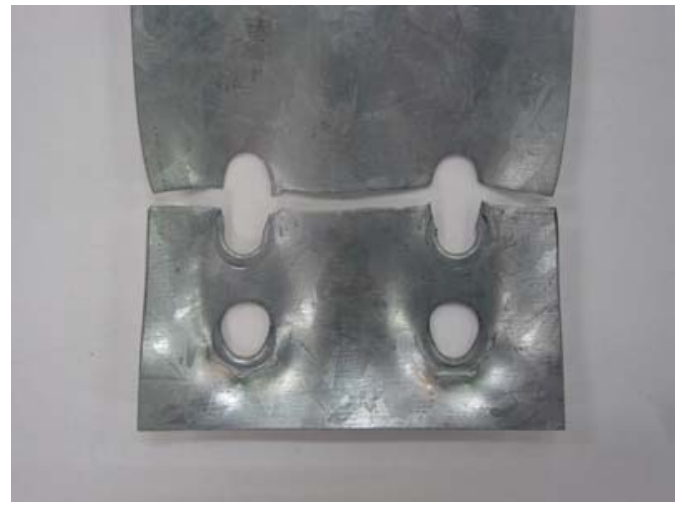

Fig. 9. $T+B+N S F$ failure.

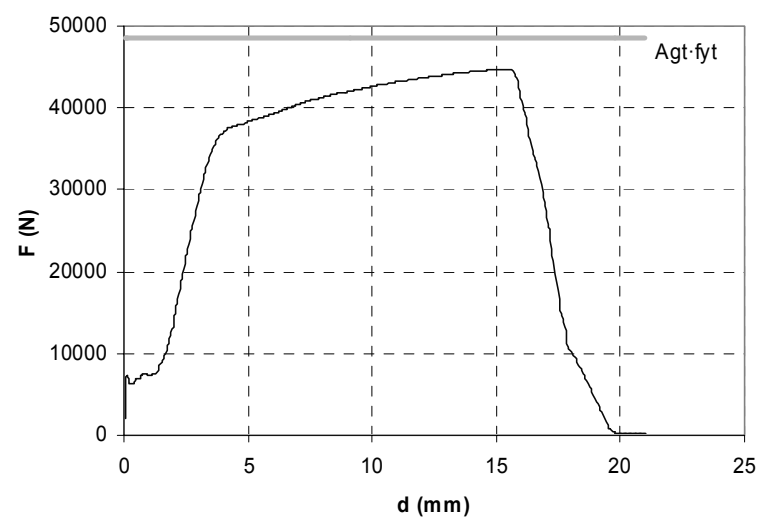

Fig. 11. F-d curve of a $T+B+N S F$ joint.

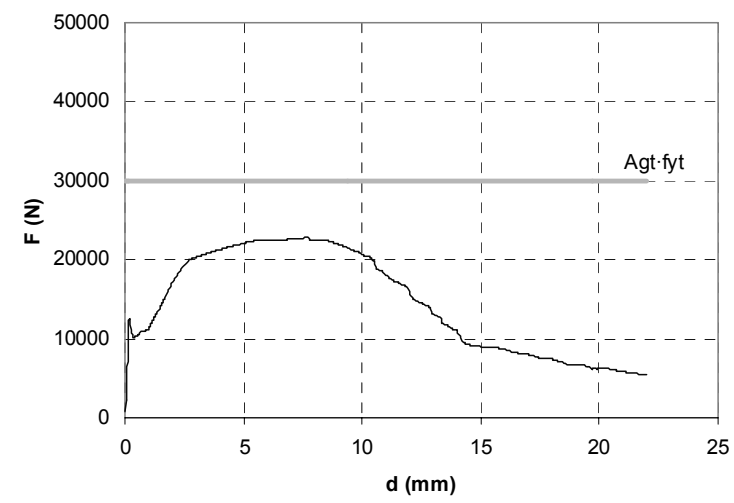

Fig. 10. F-d curve of a $T+B+T S$ joint.

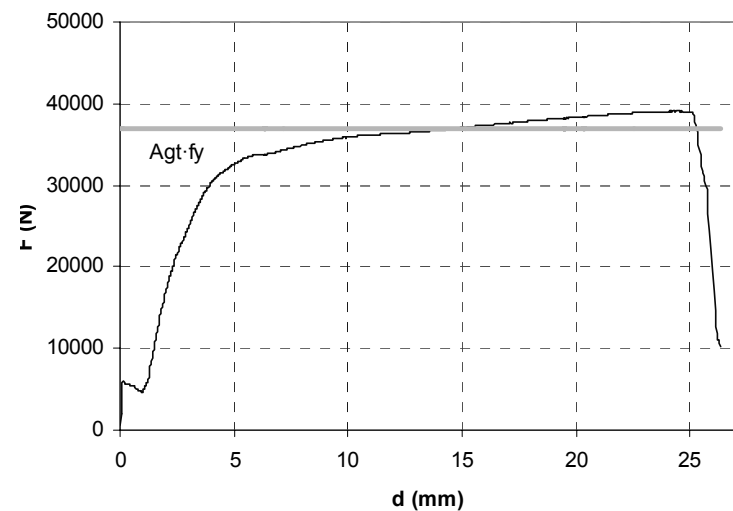

Fig. 12. F-d curve of a $T+B+T S$ joint with washers.

\section{Tests on joints between diagonal strap and gusset}

\subsection{Test specimens}

Shear tests are carried out on joints composed of diagonal straps and gussets connected by means of two rows of screws (Fig. 13). Bolts are not used because of the bad results obtained in the previous phase of the experimental campaign.

The steel grade of all the components of the joints is S250GD+Z. The nominal mechanical properties of this steel (yield stress $f_{y}$ and ultimate stress $f_{u}$ ), and their correspondent experimental values ( $f_{y t}$ and $f_{u t}$ ) are shown in Table 1 . The experimental properties were measured for the two different thickness ( $t$ ) of steel sheet used in the strap-gusset connections: 1 and $1.5 \mathrm{~mm}$.

The geometric dimensions of the 13 specimens tested are shown in Table 2, where $t_{s}$ is the nominal thickness of the strap, $t_{g}$ the nominal thickness of the gusset, and $a_{s}$ the nominal width of the strap $\left(t_{s t}, t_{g t}\right.$ and $a_{s t}$ are the measured values of these parameters). The length of the straps is either $320 \mathrm{~mm}$ or 295 $\mathrm{mm}$, depending on the number of screw columns (four or three columns). Their width is always the same: $100 \mathrm{~mm}$. All gussets have the same nominal length 


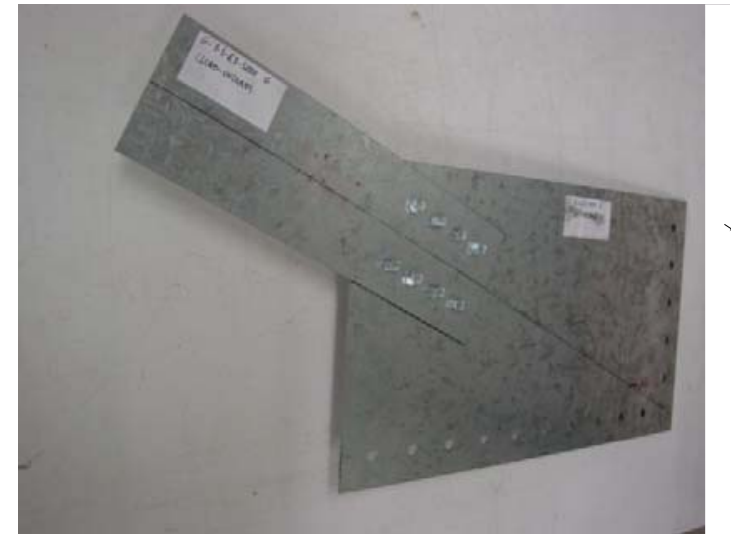

Fig. 13. Strap-gusset joint ready to be tested.

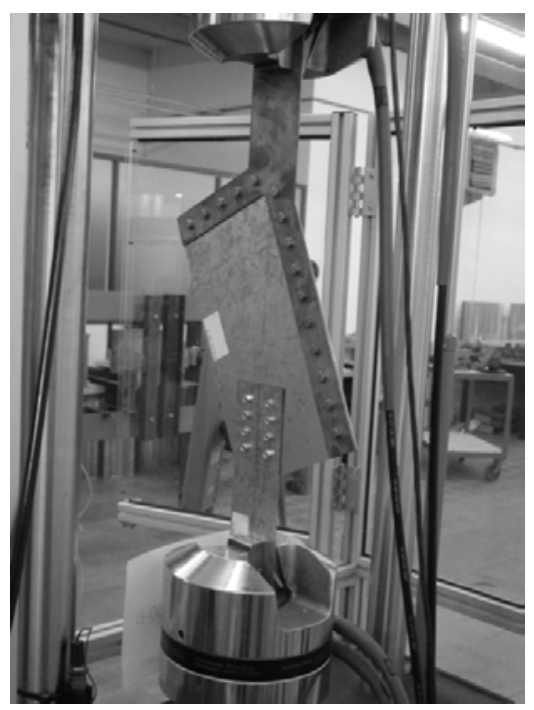

Fig. 15. Test on a gusset joint.

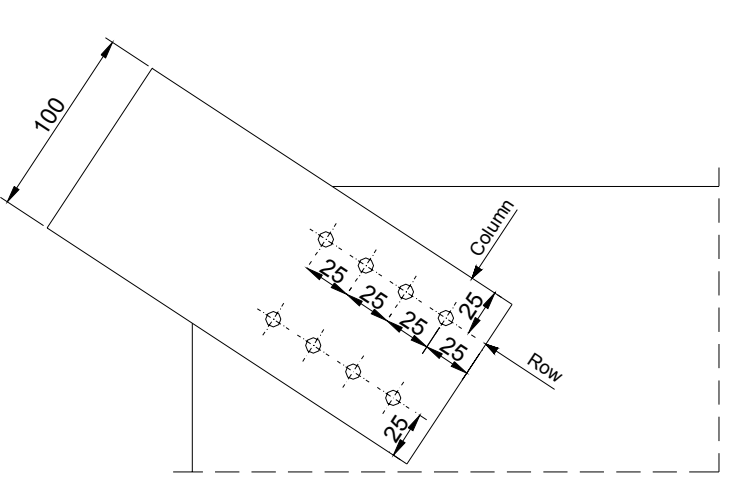

Fig. 14. Joint layout.

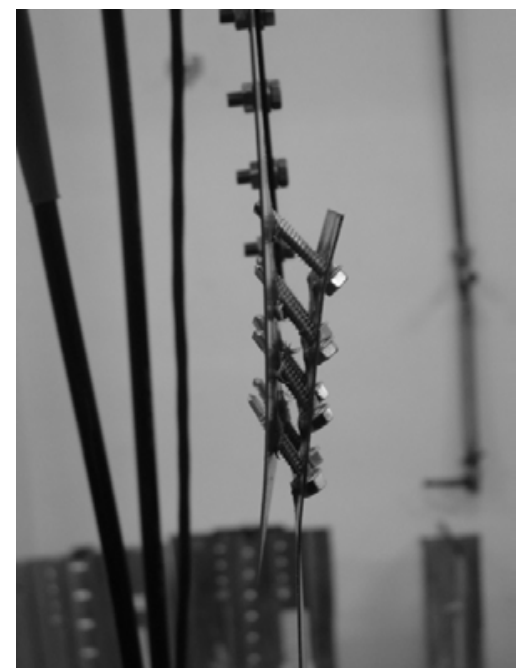

Fig. 16. $T+B+P O$ failure.

Specimen: G-1-1-6.3-S250-D.

Table 1. Steel mechanical properties for strap-gusset joints. $\mathrm{f}_{\mathrm{y}}$ : nominal yield stress, $\mathrm{f}_{\mathrm{u}}$ : nominal ultimate stress, $\mathrm{t}$ : nominal thickness, $\mathrm{f}_{\mathrm{yt}}$ : measured yield stress, $\mathrm{f}_{\mathrm{ut}}$ : measured ultimate stress.

\begin{tabular}{cccccc}
\hline Steel & $\begin{array}{c}\mathrm{f}_{\mathrm{y}} \\
\left(\mathrm{N} / \mathrm{mm}^{2}\right)\end{array}$ & $\begin{array}{c}\mathrm{f}_{\mathrm{u}} \\
\left(\mathrm{N} / \mathrm{mm}^{2}\right)\end{array}$ & $\begin{array}{c}\mathrm{t} \\
(\mathrm{mm})\end{array}$ & $\begin{array}{c}\mathrm{f}_{\mathrm{yt}} \\
\left(\mathrm{N} / \mathrm{mm}^{2}\right)\end{array}$ & $\begin{array}{c}\mathrm{f}_{\mathrm{ut}} \\
\left(\mathrm{N} / \mathrm{mm}^{2}\right)\end{array}$ \\
\hline S250GD+Z & 250 & 330 & 1 & 303 & 393 \\
& & & 1.5 & 317 & 391 \\
\hline
\end{tabular}

and width: $450 \times 250 \mathrm{~mm}$. The straps can be connected by means of two different screws, either $4.8 \mathrm{~mm}$ or $6.3 \mathrm{~mm}$ diameter screws. Fig. 14 shows the joint layout, which is identical for all the specimens.

The meaning of the joint notation used in the first column of Table 2 is explained with the following example:

$$
G-t_{1}-t_{2}-\Phi-s g-I(G-1-1-6.3-S 250-A)
$$


Table 2. Main dimensions of strap-gusset joints (in $\mathrm{mm}$ ).

$\mathrm{t}_{\mathrm{s}}$ : nominal thickness of the strap, $\mathrm{t}_{\mathrm{g}}$ : nominal thickness of the gusset, $\mathrm{a}_{\mathrm{s}}$ : nominal width of the strap, $\mathrm{t}_{\mathrm{st}}$ : measured thickness of the strap, $\mathrm{t}_{\mathrm{gt}}$ : measured thickness of the gusset, $\mathrm{a}_{\mathrm{st}}$ : measured width of the strap.

\begin{tabular}{ccccccc}
\hline Connection & $\mathrm{t}_{\mathrm{s}}$ & $\mathrm{t}_{\mathrm{g}}$ & $\mathrm{a}_{\mathrm{s}}$ & $\mathrm{t}_{\mathrm{st}}$ & $\mathrm{t}_{\mathrm{gt}}$ & $\mathrm{a}_{\mathrm{st}}$ \\
\hline G-1-1-4.8-S250-A & 1 & 1 & 100 & 1.04 & 1.06 & 100 \\
G-1-1-4.8-S250-B & 1 & 1 & 100 & 1.05 & 1.06 & 100 \\
G-1-1-6.3-S250-A & 1 & 1 & 100 & 1.04 & 1.05 & 100 \\
G-1-1-6.3-S250-B & 1 & 1 & 100 & 1.04 & 1.03 & 100 \\
G-1-1-6.3-S250-C & 1 & 1 & 100 & 1.04 & 1.04 & 99,9 \\
G-1-1-6.3-S250-D & 1 & 1 & 100 & 1.04 & 1.05 & 100 \\
G-1-1-6.3-S250-E & 1 & 1 & 100 & 1.04 & 1.05 & 100 \\
G-1-1-6.3-S250-F & 1 & 1 & 100 & 1.03 & 1.04 & 100 \\
G-1-1-6.3-S250-G & 1 & 1 & 100 & 1.04 & 1.04 & 99,9 \\
G-1-1.5-4.8-S250 & 1 & 1.5 & 100 & 1.02 & 1.60 & 100 \\
G-1-1.5-6.3-S250 & 1 & 1.5 & 100 & 1.04 & 1.59 & 100 \\
G-1.5-1,5-4.8-S250 & 1.5 & 1.5 & 100 & 1.56 & 1.59 & 100 \\
G-1.5-1.5-6.3-S250 & 1.5 & 1.5 & 100 & 1.57 & 1.58 & 100 \\
\hline
\end{tabular}

G: gusset joint, $t_{1}$ : thickness of the strap $\left(t_{1}=1 \mathrm{~mm}\right), t_{2}$ : thickness of the gusset $\left(\mathrm{t}_{2}=1 \mathrm{~mm}\right), \Phi$ : diameter of the screw $(\Phi=6.3 \mathrm{~mm})$, sg: steel grade (S250GD+Z), l: letter used when there are two or more identical joints $(A)$.

\subsection{Test procedure}

The test procedure is similar to the one followed when testing the strap-strap joints. The first operation is to measure the actual dimensions of the specimens (see some of the measured values in Table 2 and the full collection of measurements in [16]). Afterwards, the specimens are labelled and a line is drawn along the axis of the straps. This line is used to centre the joint in the testing machine (see Fig. 13).

The main difference with the test setup of strap joints (see [7]) is that a special support plate (y-plate) is used to connect the gusset to the grip of the testing machine (Fig. 15). This y-plate is $3 \mathrm{~mm}$ thick and is fastened to the specimens by means of 15 bolts $(\phi=8 \mathrm{~mm})$. The strap is assembled to the gusset in such a way that it is subject to pure tension, i.e., the axis of the strap is collinear to the axis of the y-plate.

A $250 \mathrm{kN}$ universal testing machine is used to load the joints. Tests are displacement-controlled and the load is applied at a rate of $0.01 \mathrm{~mm} / \mathrm{s}$ when the elongation of the joint is lower than $2 \mathrm{~mm}$; and at a rate of $0.02 \mathrm{~mm} / \mathrm{s}$ when the elongation is higher. Every 0.04 millimetres, the applied force and the length increment of the joint are measured and stored in a computer.

\subsection{Modes of failure}

Many different phenomena are observed during the tests on strap-gusset joints. Nevertheless, it is possible to distinguish three main modes of failure: 
$-\mathrm{T}+\mathrm{B}+\mathrm{PO}$, combination of tilting $(\mathrm{T})$ and bearing $(\mathrm{B})$, and final failure due to pull out (PO) of the screws (Fig. 16);

$-\mathrm{T}+\mathrm{B}+\mathrm{NSF}$, combination of tilting $(\mathrm{T})$ and bearing $(\mathrm{B})$, and final failure due to net section failure (NSF) of the strap (Fig. 17);

$-T+S F S$, tilting (T) and shear failure of the screws (SFS) (Fig. 18).

The $\mathrm{T}+\mathrm{B}+\mathrm{PO}$ and $\mathrm{T}+\mathrm{B}+\mathrm{NSF}$ failure modes are similar to the ones observed in the previously performed tests on screwed strap-strap joints. It was not expected that there would be specimens undergoing shear failure of screws, as it finally occurs to the joints connecting straps of $1.5 \mathrm{~mm}$ in thickness. The problem is that it was considered convenient to reduce the number of screw columns of these joints because the bearing area available was higher than in joints with $1 \mathrm{~mm}$ thick straps. However, this decision was a mistake since in the end this reduction in the number of columns, together with the increase of the load carrying capacity of the strap, provoked the failure of the screws.

Table 3 shows the modes of failure, the experimental ultimate loads $\left(P_{u t}\right)$ and the design failure loads $\left(P_{u d}\right)$ calculated according to Eurocode 3 [17]. It can be observed that design ultimate strengths of $\mathrm{T}+\mathrm{B}+\mathrm{PO}$ joints, determined with the

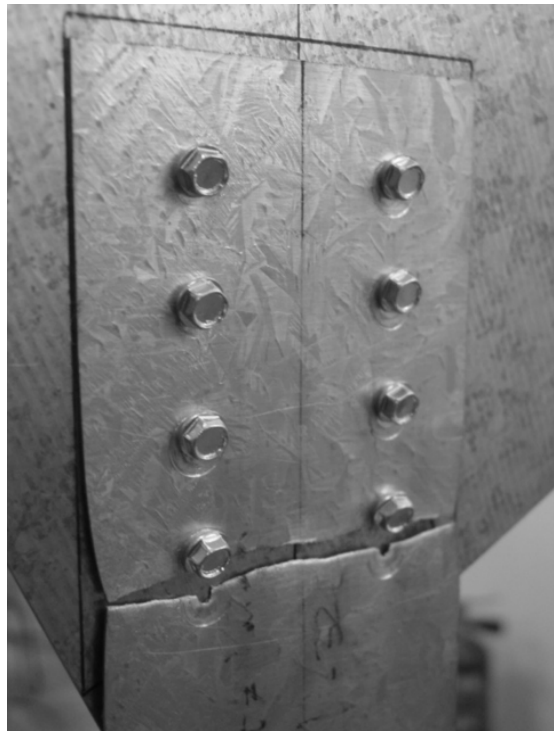

Fig. 17. $T+B+N S F$ failure.

Specimen: G-1-1.5-4.8-S250.

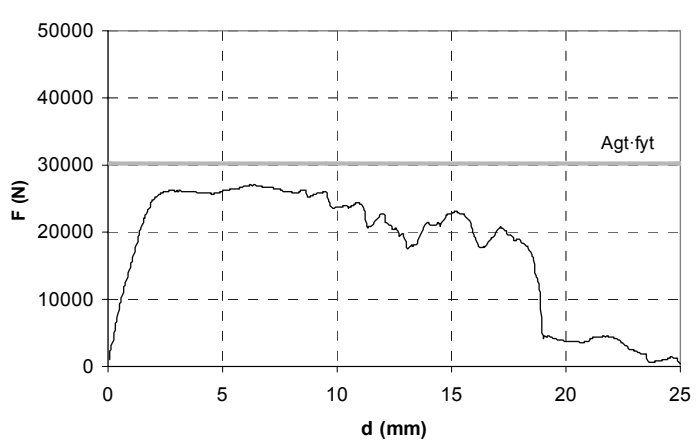

Fig. 19. F-d curve of a $T+B+P O$ joint. Specimen:G-1-1-6.3-S250-E.

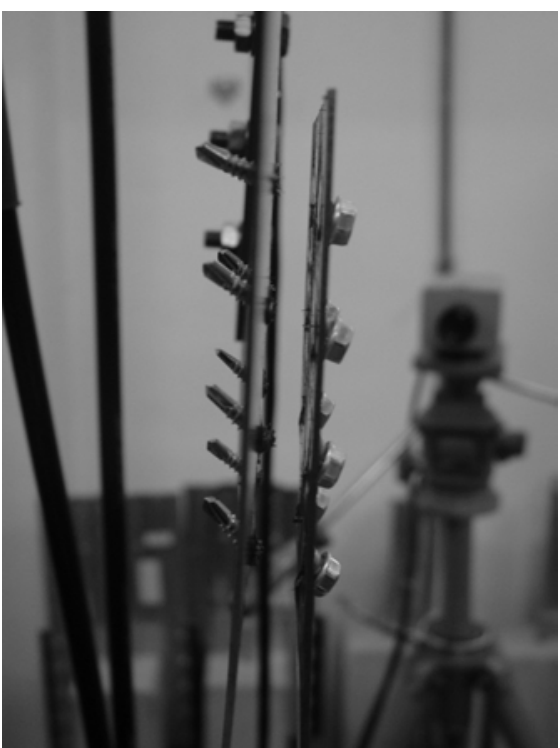

Fig. 18. T+SFS failure.

Specimen: G-1-1-6.3-S250-D

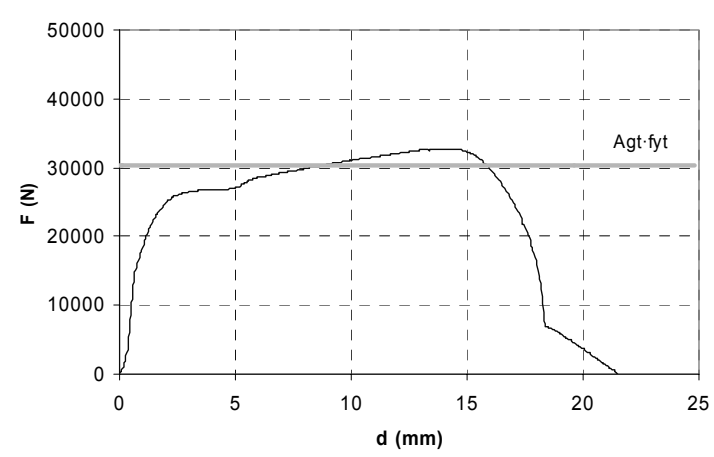

Fig. 20. F-d curve of a $T+B+N S F$ joint. Specimen:G-1-1.5-6.3-S250. 
Table 3. Results of tests and calculations on strap-gusset joints.

$\mathrm{P}_{\mathrm{ut}}$ : experimental ultimate load, $\mathrm{P}_{\mathrm{Rd}}$ : calculated ultimate load, $\mathrm{r}_{\mathrm{d}}$ : displacement ductility ratio, $\mathrm{r}_{\mathrm{f}}$ : force ductility ratio.

\begin{tabular}{cccccc}
\hline Connection & $\begin{array}{c}\text { Failure } \\
\text { mode }\end{array}$ & $\begin{array}{c}\mathrm{P}_{\mathrm{ut}} \\
(\mathrm{N})\end{array}$ & $\begin{array}{c}\mathrm{P}_{\mathrm{Rd}} \\
(\mathrm{N})\end{array}$ & $\mathrm{r}_{\mathrm{d}}$ & $\mathrm{r}_{\mathrm{f}}$ \\
\hline G-1-1-4.8-S250-A & T+B+PO & 32482 & 27713 & 12.31 & 1.07 \\
G-1-1-4.8-S250-B & T+B+PO & 32732 & 28046 & 9.12 & 1.07 \\
G-1-1-6.3-S250-A & T+B+PO & 27466 & 25361 & 3.33 & 0.91 \\
G-1-1-6.3-S250-B & T+B+PO & 27781 & 24874 & 3.88 & 0.92 \\
G-1-1-6.3-S250-C & T+B+PO & 27208 & 25252 & 5.83 & 0.90 \\
G-1-1-6.3-S250-D & T+B+PO & 27466 & 25524 & 3.59 & 0.91 \\
G-1-1-6.3-S250-E & T+B+PO & 27009 & 25361 & 4.64 & 0.89 \\
G-1-1-6.3-S250-F & T+B+PO & 27776 & 24874 & 6.73 & 0.93 \\
G-1-1-6.3-S250-G & T+B+PO & 26966 & 25252 & 5.63 & 0.89 \\
G-1-1.5-4.8-S250 & T+B+NSF & 34254 & 34974 & 12.82 & 1.15 \\
G-1-1.5-6.3-S250 & T+B+NSF & 32689 & 34340 & 8.58 & 1.08 \\
G-1.5-1.5-4.8-S250 & T+SFS & 47432 & 41396 & 3.24 & 0.99 \\
G-1.5-1.5-6.3-S250 & T+SFS & 40752 & 35894 & 2.04 & 0.84 \\
\hline
\end{tabular}

Eurocode bearing equation, are conservatively predicted; while the ultimate strength of $\mathrm{T}+\mathrm{B}+\mathrm{NSF}$ is slightly overestimated. The same trend could be seen in the tests of strap joints. When strap and gusset have different thickness, the design strength for the $\mathrm{T}+\mathrm{B}+\mathrm{PO}$ failure is so low that the mode of collapse can not be correctly predicted. These problems are fully discussed in [7].

\subsection{Force-displacement curves}

Fig. 19 shows the F-d curve of specimen G-1-1-6.3-S250-E that fails T+B+PO. This curve has four branches: elastic, yielding, hardening and failure. The elastic and yielding branches are clearly defined, while the hardening branch is very short because the pull-out phenomenon (failure branch) does not allow it to develop.

On the contrary, the hardening branch can be perfectly seen in $\mathrm{T}+\mathrm{B}+\mathrm{NSF}$ joints (Fig. 20), which also show elastic and yielding branches, and sudden failure after the maximum load is reached.

The behaviour of the joints that undergo the third mode of failure, the T+SFS joints, is similar to the behaviour of $\mathrm{T}+\mathrm{B}+\mathrm{PO}$ joints. It should be noted, however, that the failure may occur earlier, as shown in Fig. 21, where only elastic and yielding branches are observed.

Finally, the behaviour of strap-gusset joints and the behaviour of a strap-strap joints is compared. This comparison is performed by means of the gusset specimen G-1-1-6.3-S250 that has a companion joint in the experimental campaign on strap connections. Fig. 22 shows that both specimens behave in a similar way. There is only one small difference: the failure branch of the strap joint is shorter than in the gusset joint. This difference is due to the fact that the 


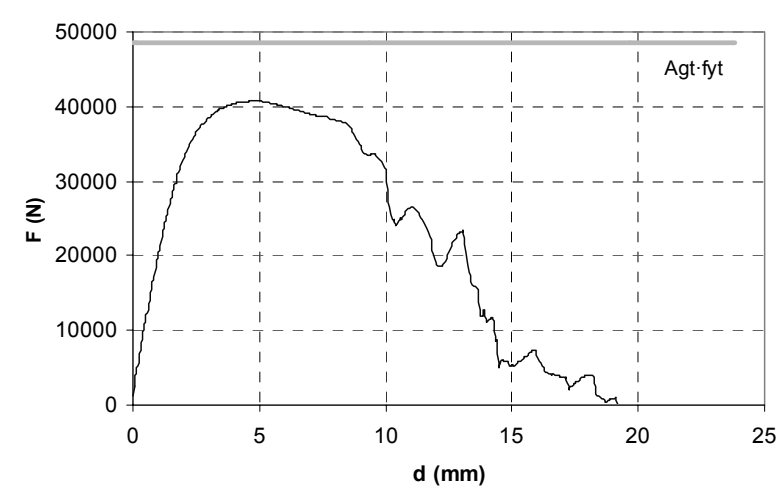

Fig. 21. F-d curve of a T+SFS joint. Specimen:G-1.5-1.5-6.3-S250.

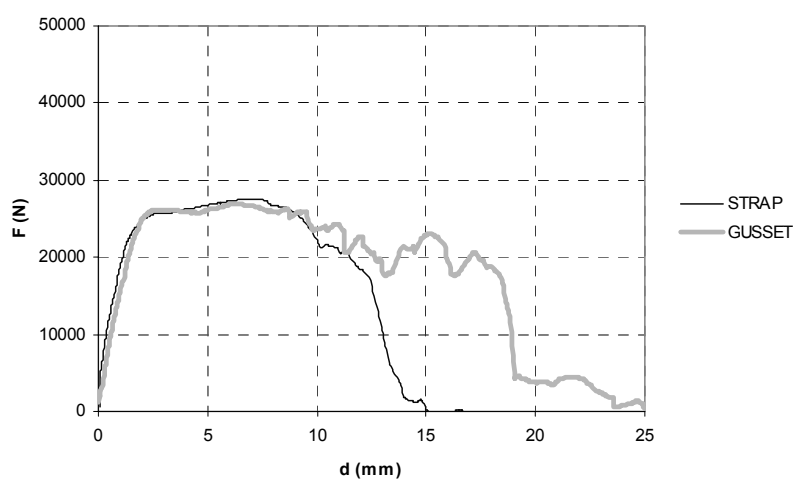

Fig. 22. F-d curves of strap and gusset joints. Specimens:G-1-6.3-S250.

screws used in strap joints are shorter than the screws used in gusset joints, and, as a consequence, the pull-out process is not so long.

\subsection{Ductility of the connection}

The ductility of joints is studied by means of the displacement ductility ratio $r_{d}=d_{u} / d_{y}$ shown in Table 3 , where $d_{u}$ is the displacement corresponding to the ultimate load, and $d_{y}$ is the displacement at yielding.

The joints tested can be considered ductile, because they show ductility ratios higher than 2 (Fig. 23 and Table 3). From the small set of test results, it can also be observed that the degree of ductility depends on the mode of failure. Joints failing $T+B+N S F$ seem to be more ductile than $T+B+P O$ and $T+S F S$ joints. Therefore, from the ductility point of view, NSF joints are preferred.

On the other hand, it can also be seen that the $r_{d}$ values of T+SFS joints are rather low. These low values are in accordance with this type of failure, usually classified as non-ductile [4].

Apart from being ductile, joints of $x$-braced frames should be strong enough to allow the development of the dissipative action of straps. This can be measured by means of the force ductility ratios $r_{f}$ shown in Table 3 and defined as:

$$
r_{f}=\frac{P_{u t}}{\left(A_{g t} \cdot f_{y t}\right)}
$$

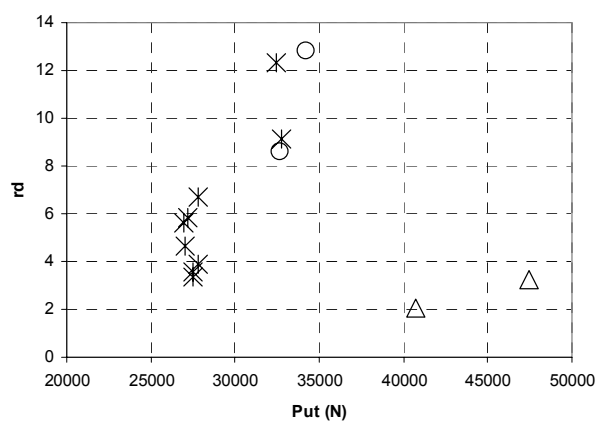

Fig. 23. Displacement ratio vs. ultimate load of strap-gusset joints.

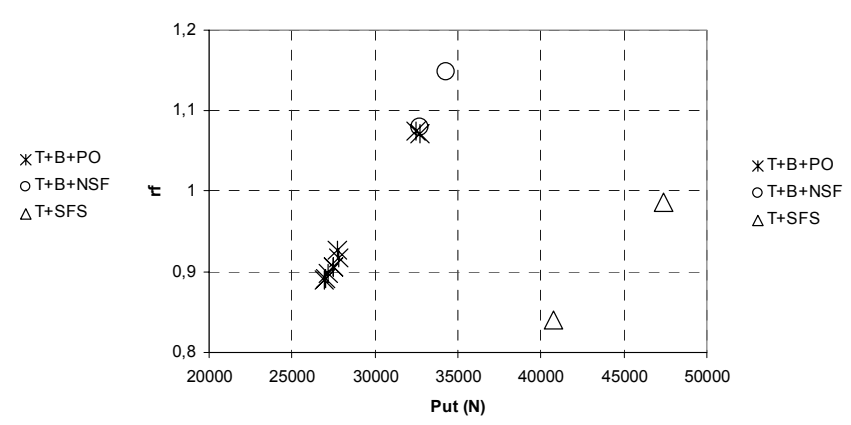

Fig. 24. Force ductility ratio vs. ultimate load of strap-gusset joints. 
This is the ratio between the ultimate load of the joint $\left(P_{u t}\right)$ and the yielding load of the diagonal strap $\left(A_{g t} \cdot f_{y t}\right)$. When the ratio is higher than 1 , the joint has a good seismic behaviour, because it fails once the strap has already yielded and, as a consequence, the dissipative action can take place.

The $r_{f}$ values obtained for gusset joints are shown in Fig. 24 and Table 3. Only the $\mathrm{T}+\mathrm{B}+\mathrm{NSF}$ joints have all their $\mathrm{r}_{\mathrm{f}}$ ratios higher than 1 . Therefore, it can be concluded that, as it occurred in the strap-strap tests, only the NSF type of joints is suitable for seismic design. See also Figs. 19 to 21 , where it can be seen that the F-d curve corresponding to the net section failure (Fig. 20) is the only one that crosses the yielding load of the strap.

\section{Tests on lower corner joints}

\subsection{Test specimens}

Lower corner joints (Fig. 25) are tested in the next phase of the experimental campaign. Tests are performed on two different types of corner joints: lower corner joints without gussets (WOG LC joints, Fig. 26), and lower corner joints with gussets (WG LC joints, Fig. 27).

Each type of joint has its own steel properties and profiles. The components of the specimens without gussets are made of steel grade S350GD+Z; while the components of specimens with gussets are made of steel grade $S 250 G D+Z$. The properties of these steels are shown in Table 4, where $f_{y}$ is the nominal yield stress, $f_{u}$ the nominal ultimate stress, $f_{y t}$ the measured yield stress, and $f_{u t}$ the measured ultimate stress.

The main components of the WOG joints are: two thermo-slotted stud profiles C150, one thermo-slotted track profile U150 and two diagonal straps. All these members are connected by means of $4.8 \mathrm{~mm}$ diameter screws and auxiliary 12 $\mathrm{mm}$ diameter bolts. The components of the WG joints are smaller: C100 and U100 profiles in studs, U100 profiles in tracks, two gussets and two diagonal straps. These components are connected by means of $6.3 \mathrm{~mm}$ diameter screws. Table 5 shows the main dimensions of the components of the corner

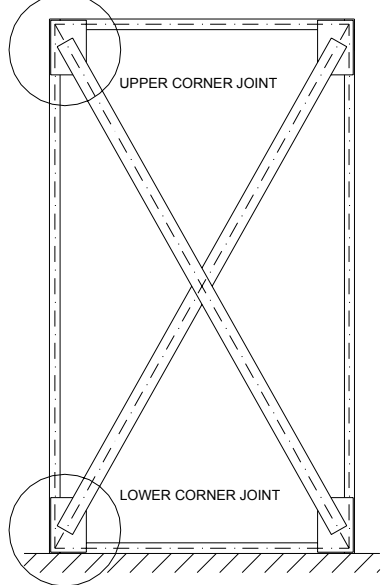

Fig. 25. Lower and upper corner joints.

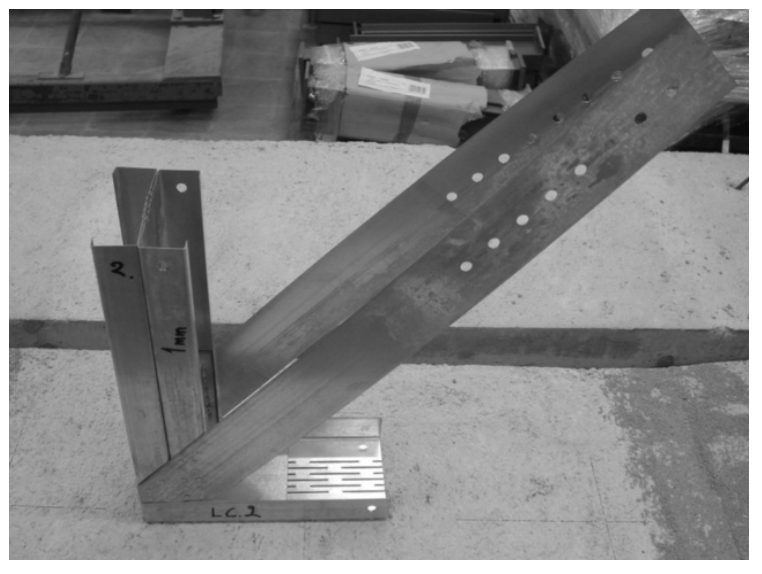

Fig. 26. Lower corner joint without gussets. 


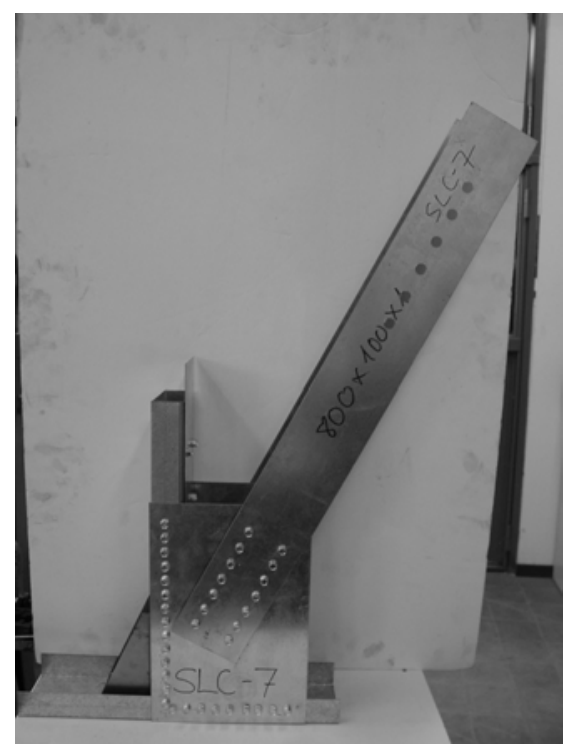

Fig. 27. Lower corner joint with gussets.

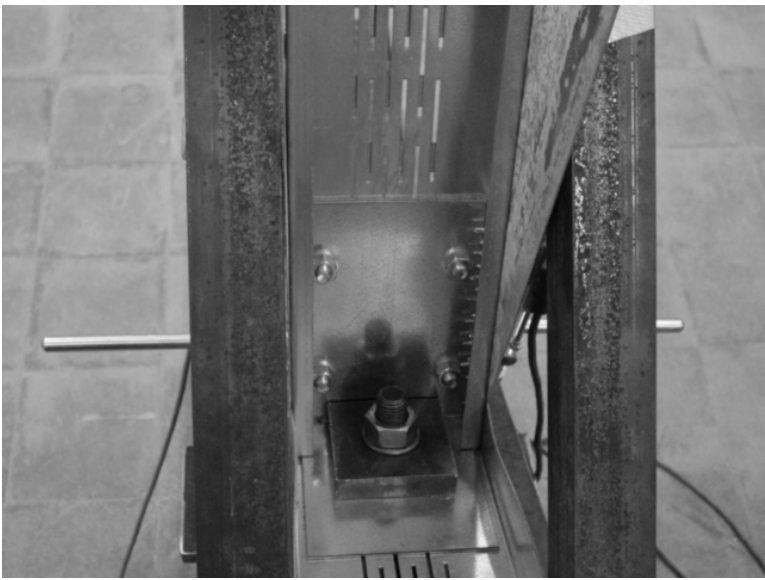

Fig. 28. Anchor bolt and washer plate in a WOG joint.

Table 4. Steel mechanical properties for LC joints (steel of diagonal straps).

$\mathrm{f}_{\mathrm{y}}$ : nominal yield stress, $\mathrm{f}_{\mathrm{u}}$ : nominal ultimate stress, $\mathrm{f}_{\mathrm{yt}}$ : measured yield stress, $\mathrm{f}_{\mathrm{ut}}$ : measured ultimate stress.

\begin{tabular}{ccccc}
\hline Connection & $\begin{array}{c}\mathrm{f}_{\mathrm{y}} \\
\left(\mathrm{N} / \mathrm{mm}^{2}\right)\end{array}$ & $\begin{array}{c}\mathrm{f}_{\mathrm{u}} \\
\left(\mathrm{N} / \mathrm{mm}^{2}\right)\end{array}$ & $\begin{array}{c}\mathrm{f}_{\mathrm{yt}} \\
\left(\mathrm{N} / \mathrm{mm}^{2}\right)\end{array}$ & $\begin{array}{c}\mathrm{f}_{\mathrm{ut}} \\
\left(\mathrm{N} / \mathrm{mm}^{2}\right)\end{array}$ \\
\hline WOG LC1-A & 350 & 420 & 394 & 506 \\
WOG LC1-B & 350 & 420 & 394 & 506 \\
WOG LC2 & 350 & 420 & 394 & 506 \\
WOG LC3-A & 350 & 420 & 394 & 506 \\
WOG LC3-B & 350 & 420 & 394 & 506 \\
WOG LC4 & 350 & 420 & 401 & 513 \\
\hline WG LC1 & 250 & 330 & 392 & 513 \\
WG LC2 & 250 & 330 & 392 & 513 \\
WG LC3 & 250 & 330 & 363 & 407 \\
WG LC4 & 250 & 330 & 363 & 407 \\
WG LC5 & 250 & 330 & 363 & 407 \\
WG LC6 & 250 & 330 & 363 & 407 \\
WG LC7 & 250 & 330 & 290 & 392 \\
WG LC8 & 250 & 330 & 392 & 513 \\
\hline
\end{tabular}

joints (st, sw and gt are the strap thickness, strap width and gusset thickness, respectively, of diagonals 1 and 2 of the connection).

Anchor bolts are used to connect the specimens to the testing device. In WOG joints, an auxiliary washer plate $(90 \times 90 \times 20 \mathrm{~mm})$ is also placed between the bolt head and the track (Figs. 28 and 30a). It should be noticed that in these specimens there is an eccentricity between the diagonal strap connection and the axis of the anchor bolt.

The WG joints tested can be classified into two groups. The joints of the first group are fastened to the testing device by means of two bolts and two hold- 


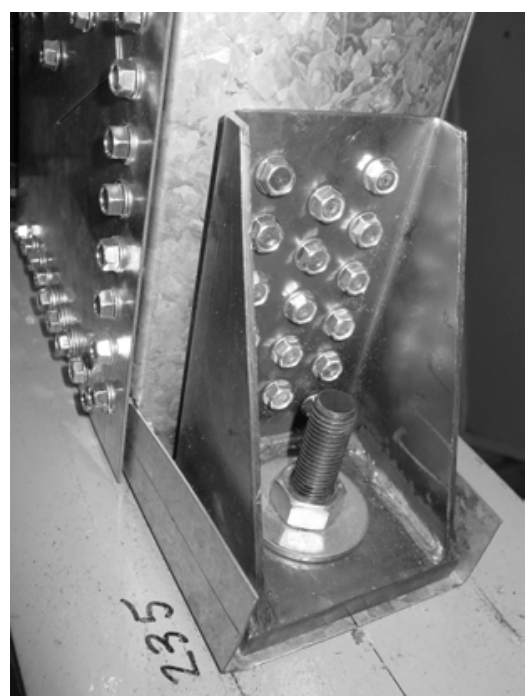

Fig. 29. Anchor bolt and hold-down plate in a WG joint.

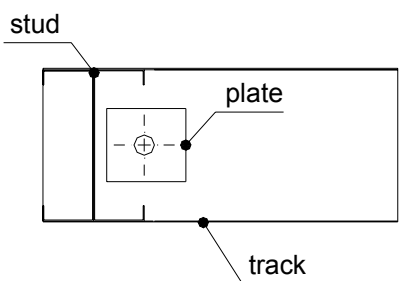

a)
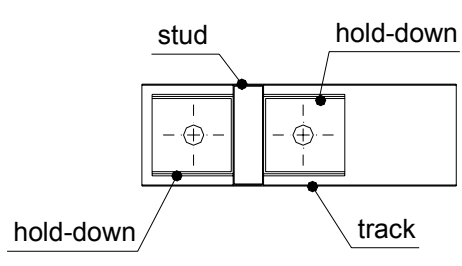

b)

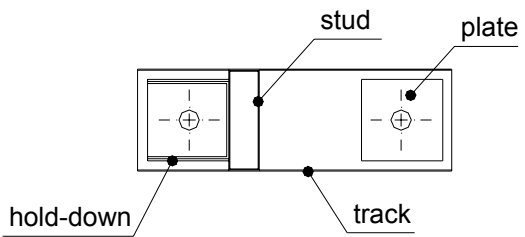

c)

Fig. 30. Three different types of lower corner joints: a) WOG joint with eccentric connection, b) WG joint without eccentricity, and c) WG joint with eccentricity.

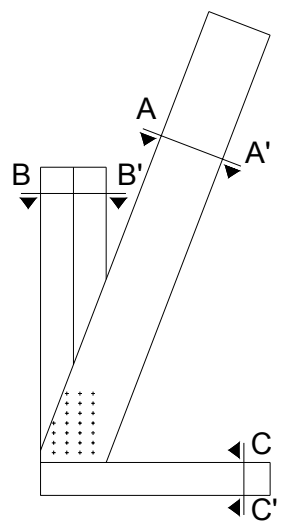

a)

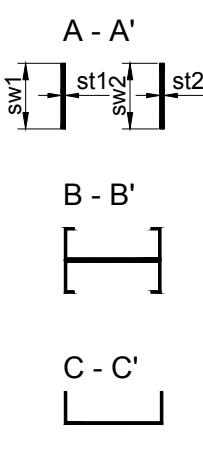

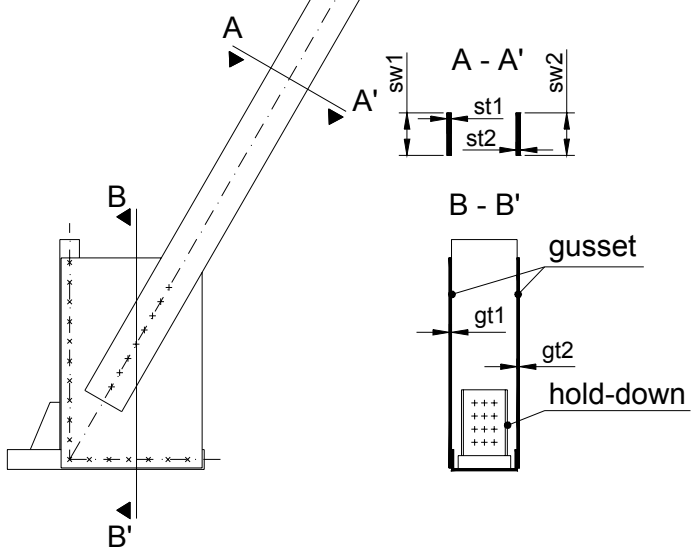

b)

Fig. 31. Dimensions measured in a) WOG joints and b) WG joints. 
Table 5. Main dimensions of LC joints (in $\mathrm{mm}$ ).

Nom. $=$ nominal values, Mea. $=$ measured values

\begin{tabular}{ccccccccccccc}
\hline \multirow{2}{*}{ Connection } & \multicolumn{3}{c}{ st $_{1}$} & \multicolumn{2}{c}{ sw $_{1}$} & \multicolumn{2}{c}{$\mathrm{gt}_{1}$} & \multicolumn{2}{c}{$\mathrm{st}_{2}$} & \multicolumn{2}{c}{$\mathrm{sw}_{2}$} & \multicolumn{2}{c}{$\mathrm{gt}_{2}$} \\
\cline { 2 - 14 } & Nom. & Mea. & Nom. & Mea. & Nom. & Mea. & Nom. & Mea. & Nom. & Mea. & Nom. & Mea. \\
\hline WOG LC1-A & 1.0 & 1.00 & 150 & 150.1 & - & - & 1.0 & 1.01 & 150 & 150.1 & - & - \\
WOG LC1-B & 1.0 & 1.01 & 150 & 150.2 & - & - & 1.0 & 1.00 & 150 & 150.1 & - & - \\
WOG LC2 & 1.0 & 0.99 & 100 & 99.8 & - & - & 1.0 & 1.02 & 100 & 100.0 & - & - \\
WOG LC3-A & 1.0 & 1.01 & 150 & 150.1 & - & - & 1.0 & 1.02 & 150 & 150.7 & - & - \\
WOG LC3-B & 1.0 & 1.01 & 150 & 150.8 & - & - & 1.0 & 1.01 & 150 & 150.3 & - & - \\
WOG LC4 & 1.5 & 1.50 & 150 & 150.1 & - & - & 1.5 & 1.51 & 150 & 150.8 & - & - \\
\hline WG LC1 & 1.0 & 0.99 & 100 & 100.2 & 1.0 & 0.99 & 1.0 & 0.99 & 100 & 100.3 & 1.0 & 0.98 \\
WG LC2 & 1.0 & 0.99 & 100 & 100.2 & 1.5 & 1.49 & 1.0 & 0.99 & 100 & 100.1 & 1.5 & 1.48 \\
WG LC3 & 1.0 & 1.01 & 65 & 65.2 & 1.0 & 0.99 & 1.0 & 1.01 & 65 & 65.0 & 1.0 & 0.98 \\
WG LC4 & 1.0 & 1.01 & 65 & 65.1 & 1.5 & 1.49 & 1.0 & 1.02 & 65 & 65.1 & 1.5 & 1.48 \\
WG LC5 & 1.0 & 1.01 & 65 & 65.1 & 1.0 & 0.99 & 1.0 & 1.02 & 65 & 65.1 & 1.0 & 0.99 \\
WG LC6 & 1.0 & 1.02 & 65 & 65.1 & 1.5 & 1.52 & 1.0 & 1.01 & 65 & 65.1 & 1.5 & 1.51 \\
WG LC7 & 1.0 & 0.99 & 100 & 100.8 & 1.0 & 0.98 & 1.0 & 1.01 & 100 & 100.4 & 1.0 & 1.02 \\
WG LC8 & 1.0 & 1.01 & 100 & 100.1 & 1.5 & 1.49 & 1.0 & 0.99 & 100 & 100.2 & 1.5 & 1.50 \\
\hline
\end{tabular}

down plates (Figs. 29 and 30), one at each side of the stud. These two bolts are placed in such a way that it can be considered that there is not eccentricity in the connection, see Fig. 30b. On the other side, the eccentric connection shown in Fig. 30c is used for the second group of WG joints. In this case, the inner hold-down plate is substituted by a conventional washer plate.

\subsection{Test procedure}

Only one operation is performed before testing: the main dimensions of the joints are measured. Fig. 31 and Table 5 show the measurements taken. Afterwards, lower corner joints are loaded in a device specially designed and constructed for the testing campaign (Figs. 32 and 33). The specimens are connected to a steel U-profile (upper U-profile in Fig. 32) by means of the anchor bolts. This profile can rotate so that the diagonal straps, whose angle with respect to the studs and track is not the same for all the specimens, are always loaded vertically through their axis. The U-profile is fastened to a square horizontal tube by means of another auxiliary U-profile (lower U-profile). This tube allows to connect the whole test device to a concrete slab that is embedded in the floor of the laboratory.

In the upper part of the specimen, the diagonal straps are connected to a hydraulic cylinder by means of four rectangular plates, two for each diagonal. These plates have been designed to work by friction. The hydraulic cylinder hangs from a steel frame that is also anchored to the concrete slab. This test setup allows to load the specimens through their diagonals up to a tensile force of $200 \mathrm{kN}$. 


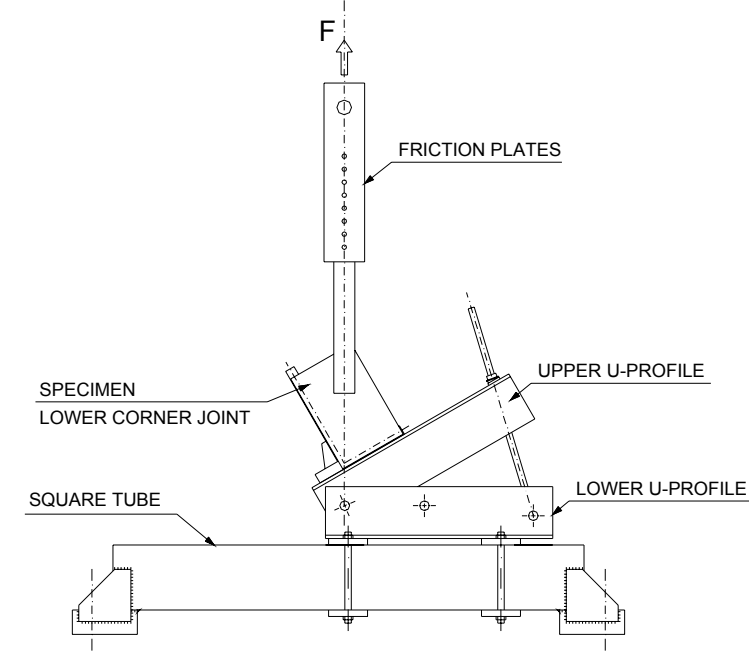

Fig. 32. Lower corner joint test setup.

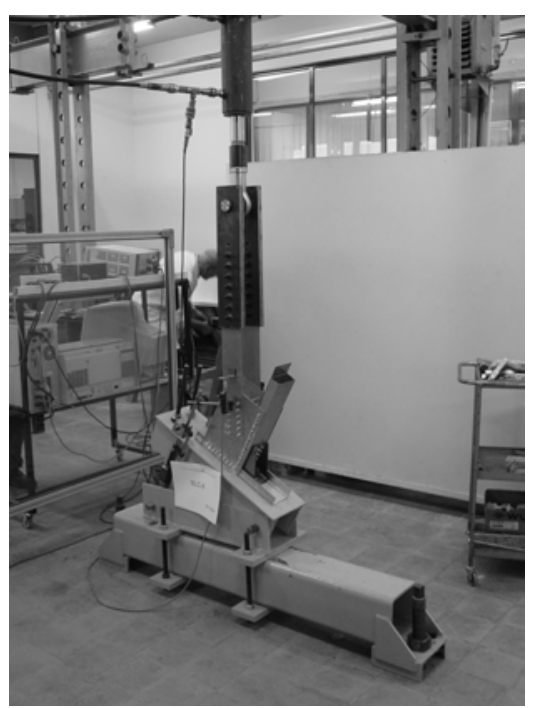

Fig. 33. Test on a lower corner joint.

Tests are force-controlled and the specimens are loaded at a rate of $150 \mathrm{~N} / \mathrm{s}$. Every 0.5 seconds, the applied force $(F)$ and the elongation of the joint (d) are measured and stored in a computer. On the basis of these data, F-d curves are drawn and the behaviour of the connections investigated.

\subsection{Test results}

Corner joints were designed to fail in the net section failure mode (NSF), which is the most advantageous type of failure, as demonstrated in the previous sections.

Table 6 shows the actual ultimate loads $\left(\mathrm{P}_{\mathrm{ut}}\right)$ and modes of failure obtained in the experimental campaign. There are joints that do fail NSF, but there are others that undergo other phenomena and failure modes. For example, WOG joints LC1 and LC4 experience a failure mode that is a combination of bending of the track and punching of its web $(L B+P)$. Firstly, the eccentricity of the anchor bolt with respect to the strap axis provokes bending deformation and local buckling collapse of the track, as it can be seen in Fig. 34. Afterwards, the final failure is caused by a sort of punching under the washer plate (Fig. 35).

The other WOG joints experience the expected NSF mode (Fig. 36). However, it is interesting to point out that in these joints a relative movement (slipping) between stud and track is usually observed before failure (Fig. 37). The stud moves until its web contacts the washer plate edge.

On the other side, all WG joints failed NSF (Fig. 38), but one, the WG LC8 specimen. There is a problem with these joints: the straps were manufactured with steel grades higher than the ones used in design calculations. See in Table 4 the nominal and measured values of the strap material properties. This resulted in overloading the connections and, as a consequence, non-desirable phenomena occurred. For instance, Fig. 39 shows a local plastification of the gusset that took place before net section failure of the strap in specimen WG LC1. 
The overloading of the connection also provoked the mentioned specimen WG LC8 to fail in a different mode than the NSF mode. Its failure is similar to the one observed in some of the WOG joints: the eccentricity of the anchor bolt connection causes the bending collapse of the track and, subsequently, punching of its web occurs (Fig. 40). It is an uplift failure of the joint that reduces the dissipative interval of the diagonal strap, as it can be seen in the last row of Table 6. For this specimen, the dissipative load ranges from $74629 \mathrm{~N}$, the yielding load of the strap $\left(A_{g} \cdot f_{y t}\right)$, to $77800 N$, the ultimate load due to the LB+P failure. If this failure had been avoided, the upper limit of the dissipative interval would have been higher, about $85384 \mathrm{~N}$, which is the calculated NSF load of the strap $\left(P_{R d}\right)$.

Bearing is not observed in any of the joints tested and tilting can only be seen in some of the WG joints.

Table 6. Results of tests and calculations on LC joints.

$\mathrm{P}_{\mathrm{ut}}$ : experimental ultimate load, $\mathrm{A}_{\mathrm{gt}}$ : measured gross cross-sectional area, $\mathrm{f}_{\mathrm{yt}}$ : measured yield stress $\mathrm{r}_{\mathrm{f}}$ : force ductility ratio, $\mathrm{P}_{\mathrm{Rd}}$ : calculated ultimate load.

\begin{tabular}{|c|c|c|c|c|c|}
\hline Connection & $\begin{array}{l}\text { Failure } \\
\text { mode }\end{array}$ & $\begin{array}{l}P_{u t} \\
(N)\end{array}$ & $\begin{array}{l}A_{g t} \cdot f_{y t} \\
(N)\end{array}$ & $r_{f}$ & $\begin{array}{l}P_{\mathrm{Rd}} \\
(\mathrm{N})\end{array}$ \\
\hline WOG LC1-A & $L B+P$ & 109520 & 113525 & 0.96 & 127172 \\
\hline WOG LC1-B & $L B+P$ & 108710 & 113555 & 0.96 & 127172 \\
\hline WOG LC2 & NSF & 83297 & 74725 & 1.11 & 82104 \\
\hline WOG LC3-A & NSF & 107091 & 114753 & 0.93 & 79120 \\
\hline WOG LC3-B & NSF & 108000 & 114868 & 0.94 & 128497 \\
\hline WOG LC4 & $\mathrm{LB}+\mathrm{P}$ & 127353 & 175732 & 0.72 & 203573 \\
\hline WG LC1 & NSF & 86380 & 74629 & 1.16 & 85384 \\
\hline WG LC2 & NSF & 88780 & 74554 & 1.19 & 85286 \\
\hline WG LC3 & NSF & 46910 & 45774 & 1.02 & 44915 \\
\hline WG LC4 & NSF & 44860 & 45845 & 0.98 & 46427 \\
\hline WG LC5 & NSF & 47560 & 45845 & 1.04 & 45470 \\
\hline WG LC6 & NSF & 45930 & 45845 & 1.00 & 46427 \\
\hline WG LC7 & NSF & 69980 & 55541 & 1.26 & 65000 \\
\hline WG LC8 & $\mathrm{LB}+\mathrm{P}$ & 77800 & 74629 & 1.04 & 85384 \\
\hline
\end{tabular}

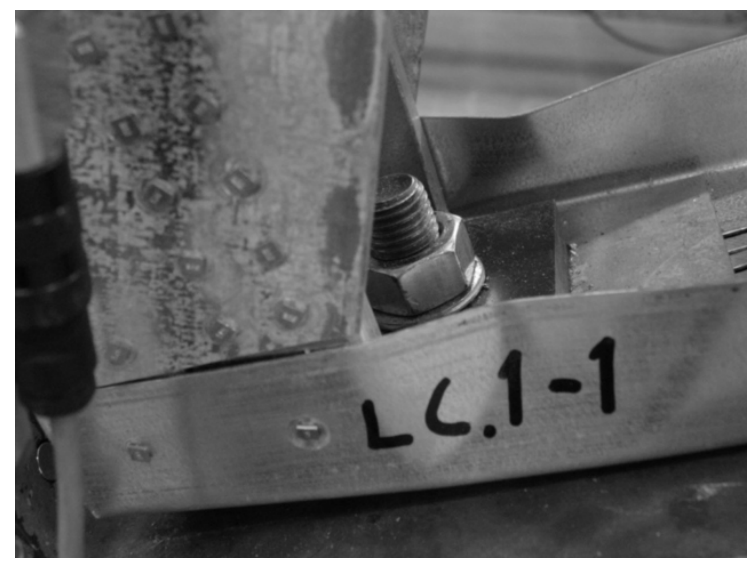

Fig. 34. Bending and local buckling of the track in specimen WOG LC1-A.

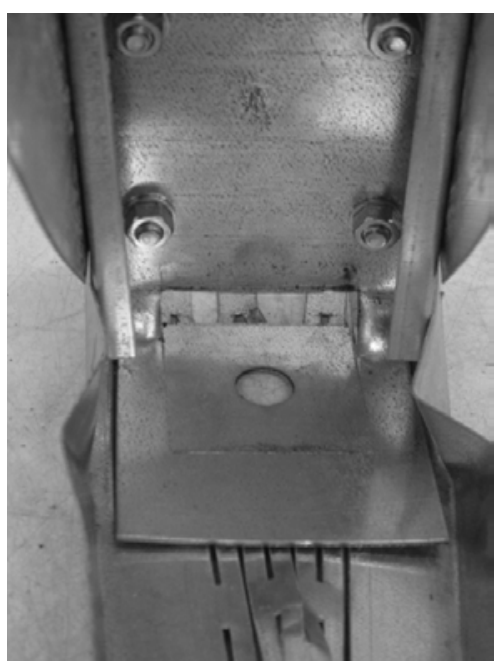

Fig. 35. Punching of the track in specimen WOG LC4. 


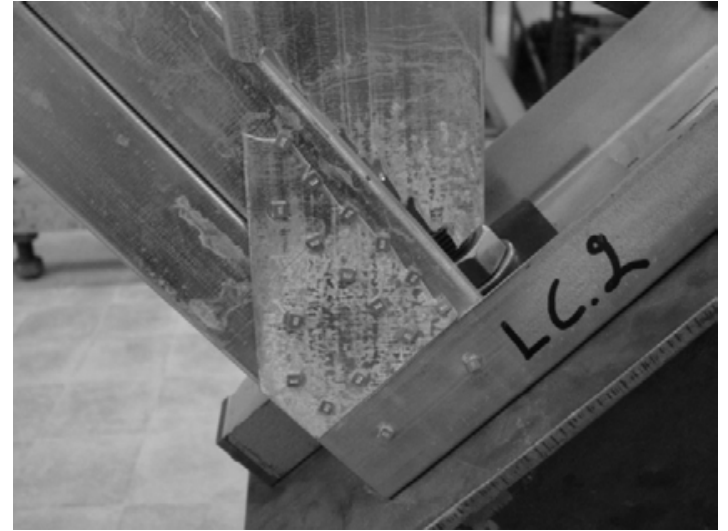

Fig. 36. Net section failure in specimen WOG LC2.

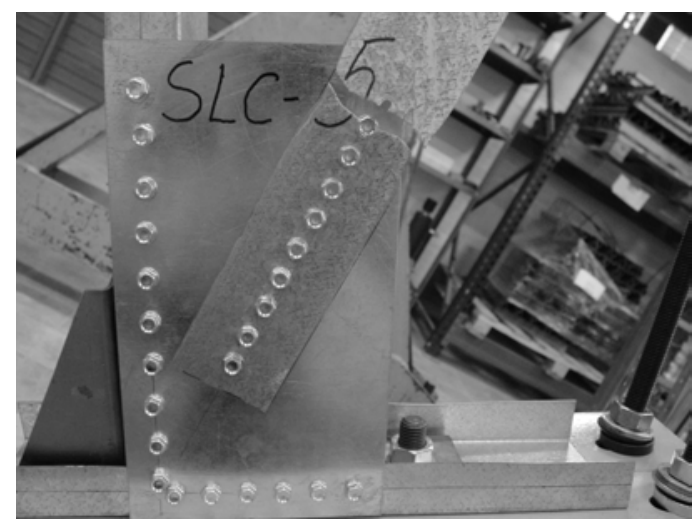

Fig. 38. Net section failure in specimen WG LC5.

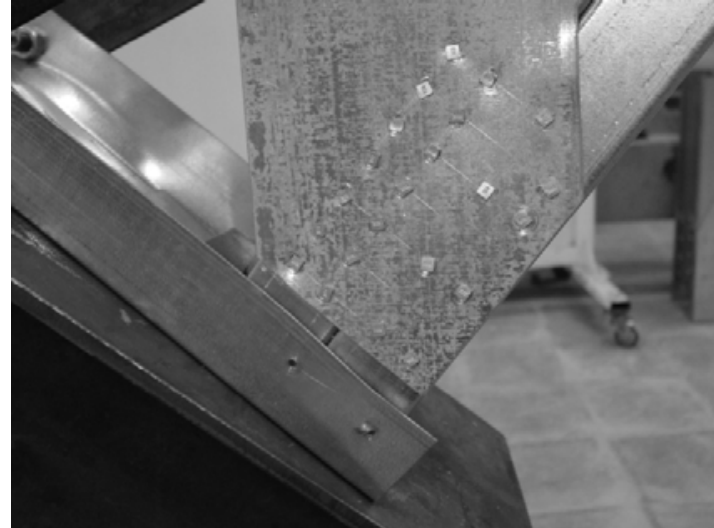

Fig. 37. Stud-track relative movement in specimen WOG LC3-A

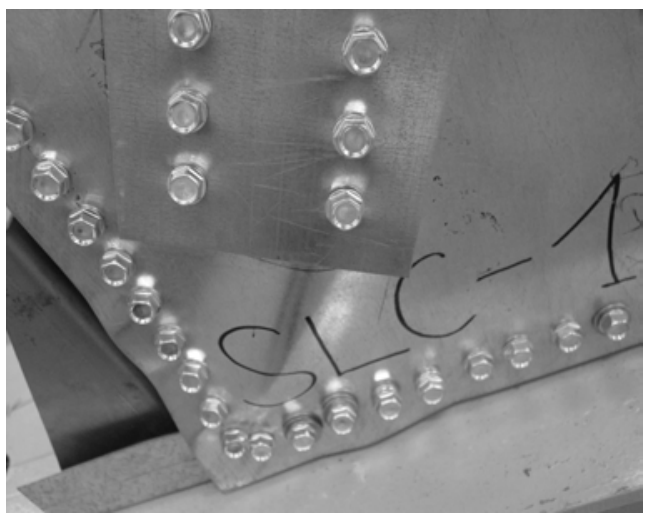

Fig. 39. Stud-track relative movement in specimen WG LC1.

The F-d curves obtained are different from those of the tests on straps and gussets. They usually have one or two branches before progressive yielding takes place. Afterwards, either failure occurs or there is a hardening branch. Many types of F-d curves are observed because there are many different phenomena occurring at different times (tilting, bending, local buckling, slipping, ...). Figs. 41 and 42 show two examples.

As in the previous sections, the force ductility ratio $\left(r_{f}\right)$ helps to decide which are the most suitable joint designs. The calculated ratios for the tested joints, included in Table 6, show that the NSF connections are again the best.

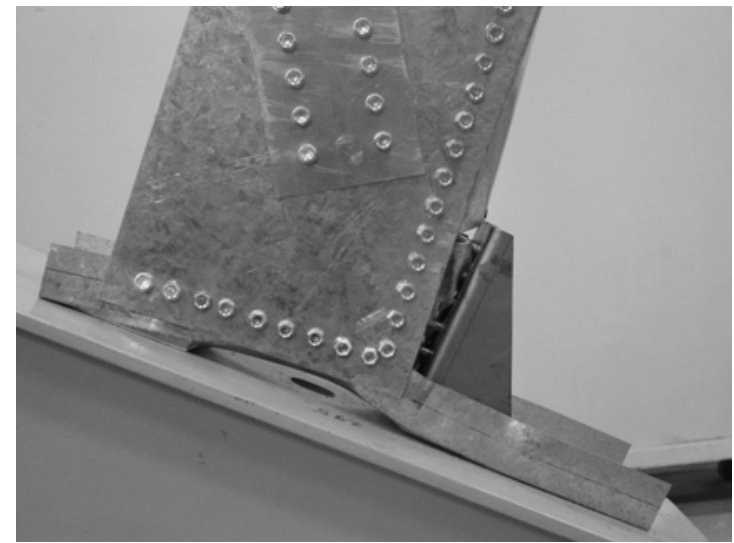

Fig. 40. Bending and punching of the track in specimen WG LC8.

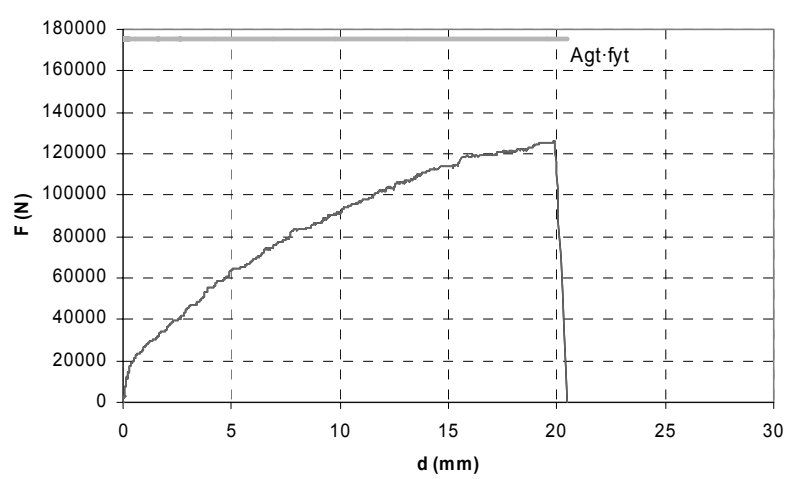

Fig. 41. Force-displacement curve of a joint failing LB+P. Specimen: WOG LC-4. 


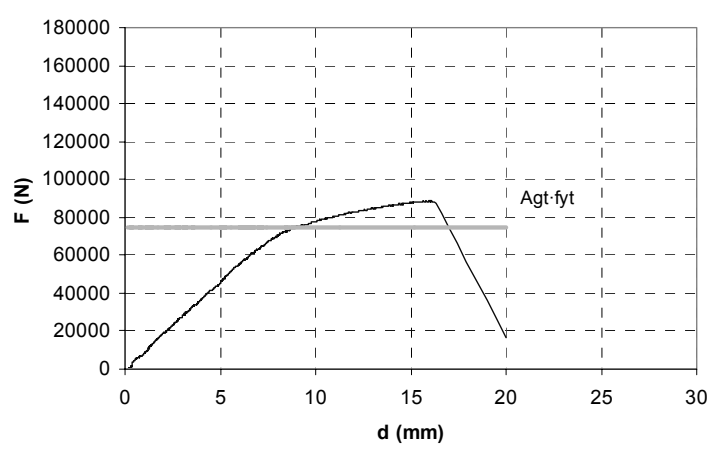

Fig. 42. Force displacement curve of a joint failing NSF. Specimen: WG LC-2.

The LB+P failure should be avoided because it does not allow the dissipative action of the diagonal straps. Reduction of the anchor bolt eccentricity and use of suitable hold-down devices can help to avoid this mode of collapse.

\section{Tests on upper corner joints}

\subsection{Test specimens}

Similar tests to those described in the previous section are performed on frame upper corner joints (Fig. 25).

The same two types of specimens are tested: joints without gussets (WOG UC joints, Fig 43) and joints with gussets (WG UC joints, Fig 44). WOG UC joints are basically composed of two thermo-slotted stud profiles C150, one or two thermo-slotted track profiles U150, and two diagonal straps. These components are connected by means of $4.8 \mathrm{~mm}$ diameter screws and auxiliary $12 \mathrm{~mm}$ diameter bolts. The main components of the WG UC joints are: one U100 profile and one $\mathrm{C} 100$ profile for studs and tracks, and two rectangular gussets and two diagonal straps. $6.3 \mathrm{~mm}$ diameter screws are used to connect all the components. Table 7 contains the main geometric dimensions of the upper corner joints tested: st strap thickness, sw strap width and gt gusset thickness for diagonals 1 and 2 .

As in the previous tests, $S 350 \mathrm{GD}+Z$ and $\mathrm{S} 250 \mathrm{GD}+Z$ steel grades are used for WOG UC and WG UC specimens, respectively (Table 8).

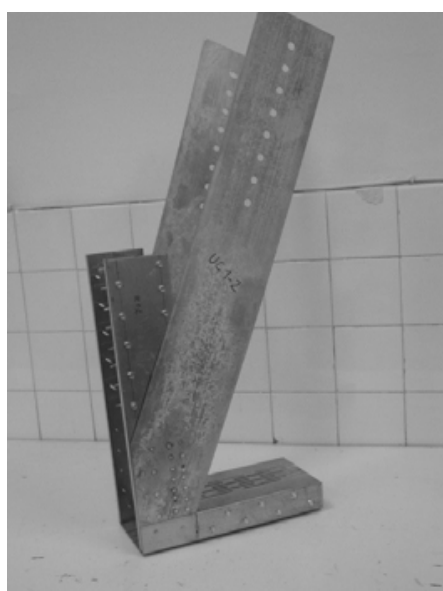

Fig. 43. Upper corner joint without gussets.

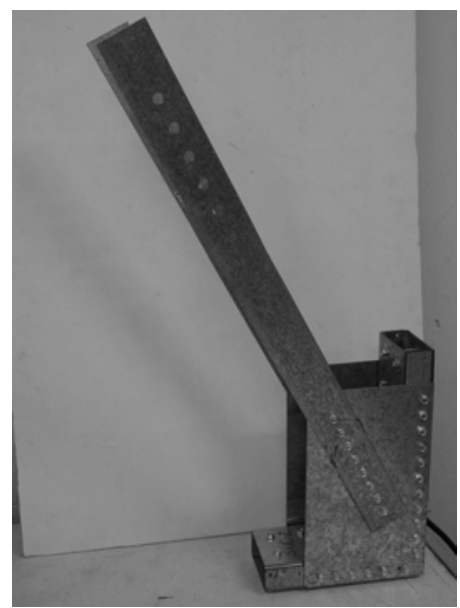

Fig. 44. Upper corner joint with gussets. 


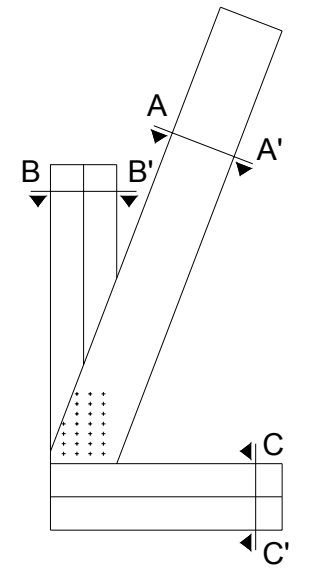

a)

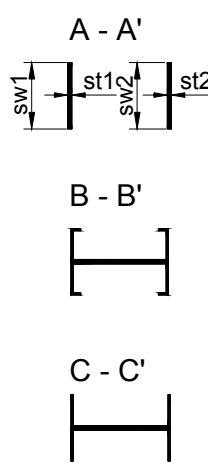

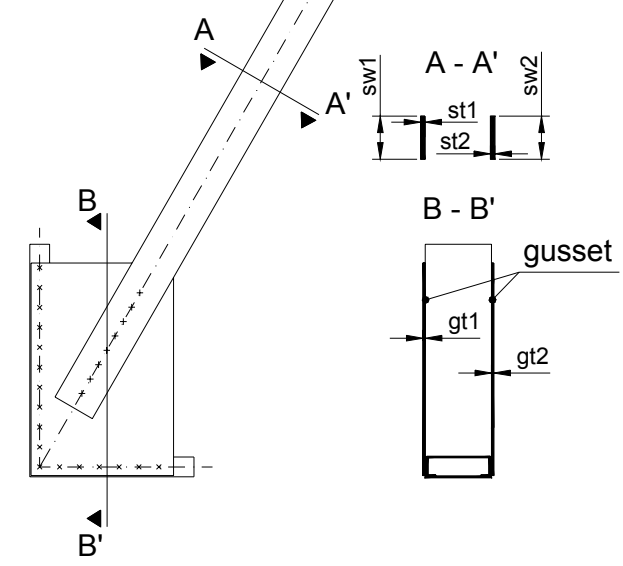

b)

Fig. 45. Dimensions measured in a) WOG joints and b) WG joints.

Table 7. Main dimensions of UC joints (in $\mathrm{mm}$ ). Nom. $=$ nominal values, Mea. $=$ measured values

\begin{tabular}{|c|c|c|c|c|c|c|c|c|c|c|c|c|}
\hline \multirow{2}{*}{ Connection } & \multicolumn{2}{|c|}{$\mathrm{st}_{1}$} & \multicolumn{2}{|c|}{$\mathrm{sw}_{1}$} & \multicolumn{2}{|c|}{$\mathrm{gt}_{1}$} & \multicolumn{2}{|c|}{$\mathrm{st}_{2}$} & \multicolumn{2}{|c|}{$\mathrm{sw}_{2}$} & \multicolumn{2}{|c|}{$\mathrm{gt}_{2}$} \\
\hline & Nom. & Mea. & Nom. & Mea. & Nom. & Mea. & Nom. & Mea. & Nom. & Mea. & Nom. & Mea. \\
\hline WOG UC1-A & 1 & 1.01 & 150 & 150.2 & - & - & 1 & 1.02 & 150 & 150.1 & - & - \\
\hline WOG UC1-B & 1 & 1.01 & 150 & 150.1 & - & - & 1 & 0.98 & 100 & 150.2 & - & - \\
\hline WOG UC2 & 1 & 1.01 & 100 & 100.1 & - & - & 1 & 0.98 & 150 & 100.2 & - & - \\
\hline WOG UC3-A & 1 & 1.00 & 150 & 150.1 & - & - & 1 & 1.00 & 150 & 150.6 & - & - \\
\hline WOG UC3-B & 1 & 1.01 & 150 & 150.5 & - & - & 1 & 1.00 & 150 & 151.3 & - & - \\
\hline WOG UC4 & 1.5 & 1.51 & 150 & 150.4 & - & - & 1.5 & 1.50 & 150 & 150.5 & - & - \\
\hline WOG UC5 & 1 & 1.01 & 150 & 150.2 & - & - & 1 & 1.03 & 150 & 150.2 & - & - \\
\hline WG UC1 & 1 & 1.01 & 65 & 65.1 & 1 & 0.99 & 1 & 1.01 & 65 & 65.1 & 1 & 0.99 \\
\hline WG UC2 & 1 & 1.01 & 65 & 65.1 & 1.5 & 1.49 & 1 & 1.00 & 65 & 65.1 & 1.5 & 1.47 \\
\hline WG UC3 & 1 & 1.00 & 100 & 101.3 & 1 & 0.99 & 1 & 0.99 & 100 & 101.1 & 1 & 0.99 \\
\hline WG UC4 & 1 & 1.01 & 100 & 101.3 & 1.5 & 1.5 & 1 & 1.00 & 100 & 101.8 & 1.5 & 1.51 \\
\hline
\end{tabular}

Table 8. Steel mechanical properties for UC joints (steel of diagonal straps).

$\mathrm{f}_{\mathrm{y}}$ : nominal yield stress, $\mathrm{f}_{\mathrm{u}}$ : nominal ultimate stress, $\mathrm{f}_{\mathrm{yt}}$ : measured yield stress, $\mathrm{f}_{\mathrm{ut}}$ : measured ultimate stress.

\begin{tabular}{ccccc}
\hline Connection & $\begin{array}{c}\mathrm{f}_{\mathrm{y}} \\
\left(\mathrm{N} / \mathrm{mm}^{2}\right)\end{array}$ & $\begin{array}{c}\mathrm{f}_{\mathrm{u}} \\
\left(\mathrm{N} / \mathrm{mm}^{2}\right)\end{array}$ & $\begin{array}{c}\mathrm{f}_{\mathrm{yt}} \\
\left(\mathrm{N} / \mathrm{mm}^{2}\right)\end{array}$ & $\begin{array}{c}\mathrm{f}_{\mathrm{ut}} \\
\left(\mathrm{N} / \mathrm{mm}^{2}\right)\end{array}$ \\
\hline WOG UC1-A & 350 & 420 & 394 & 506 \\
WOG UC1-B & 350 & 420 & 394 & 506 \\
WOG UC2 & 350 & 420 & 394 & 506 \\
WOG UC3-A & 350 & 420 & 394 & 506 \\
WOG UC3-B & 350 & 420 & 394 & 506 \\
WOG UC4 & 350 & 420 & 401 & 513 \\
WOG UC5 & 350 & 420 & 394 & 506 \\
\hline WG UC1 & 250 & 330 & 365 & 406 \\
WG UC2 & 250 & 330 & 365 & 406 \\
WG UC3 & 250 & 330 & 305 & 386 \\
WG UC4 & 250 & 330 & 305 & 386 \\
\hline
\end{tabular}




\subsection{Test procedure}

Few changes are introduced to the testing procedure. The first operation is again to measure the main dimensions of the specimens (see Fig. 45 and Table 7). Afterwards, joints are loaded in the test setup shown in Figs. 46 and 47. Some of the components of the previous lower corner joint test setup are used: the square tube, the lower U-profile, the plates through which the load is applied, and the steel frame connected to the concrete slab. A new device is designed to fasten the specimen to the tube. It consists of two hot rolled Uprofiles, connected at an angle of 90 degrees, where the specimens are placed and restrained by means of two steel plates (top plates in Fig. 46). This allows to load the specimen through the diagonal straps and prevent the displacement of the end sections of studs and tracks. This new device is hinged to the lower U-profile in such a way that the diagonal strap is not subjected to bending.

Tests are force-controlled and the specimens are loaded at a rate of $150 \mathrm{~N} / \mathrm{s}$, in the same way as for the lower corner joints.

\subsection{Test results}

The aim of this section is to describe the behaviour of the upper corner joints and the problems encountered during the testing procedure.

The first joints tested were the WOG UC2, WOG UC3-A and WOG UC5 specimens. The results obtained for these joints were rather far from those expected: the ultimate loads were too low (see $P_{u t}$ values in Table 9), and the failure affected the stud and the track, when actually these joints had been designed to fail the strap in the net section mode (NSF). Instability phenomena were the main cause of their failure. Buckling affected different parts of the specimens: the web of the inner stud, the flanges of the outer stud and the flanges of the track. For instance, see in Fig. 48 the local buckling instability observed in specimen WOG UC2.

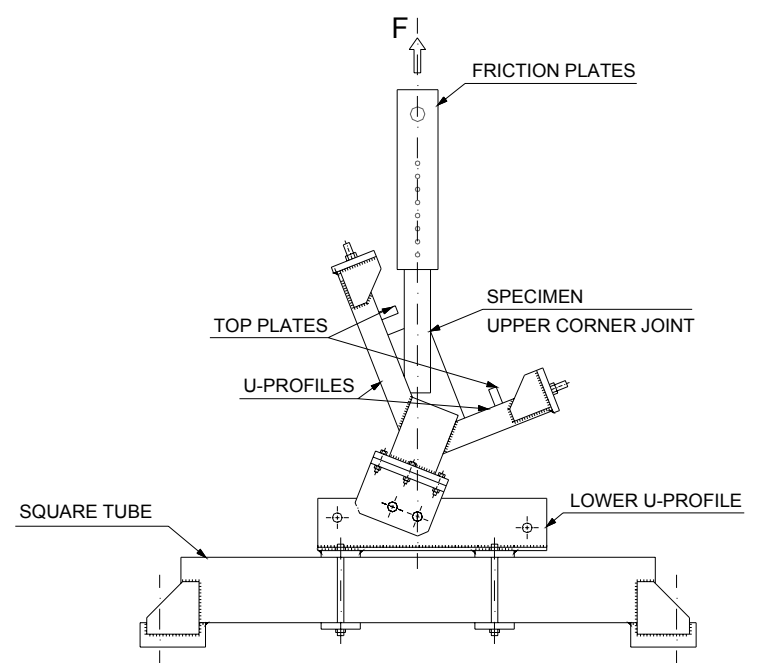

Fig. 46. Upper corner joints test setup.

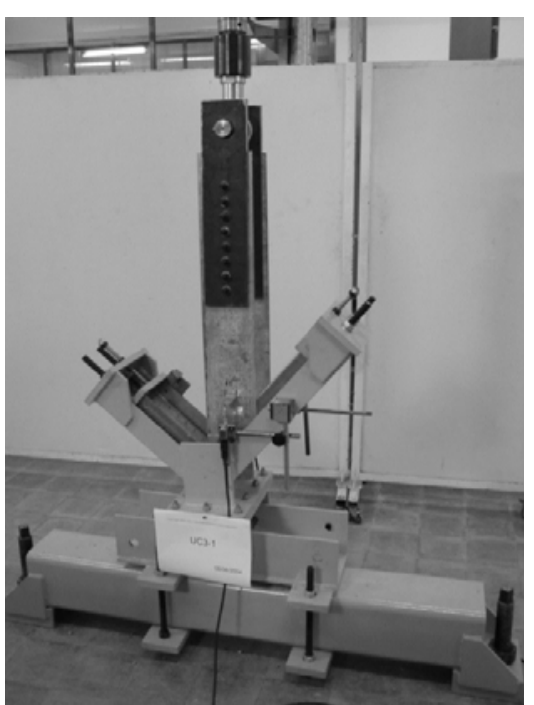

Fig. 47. Test on an upper corner joint. 


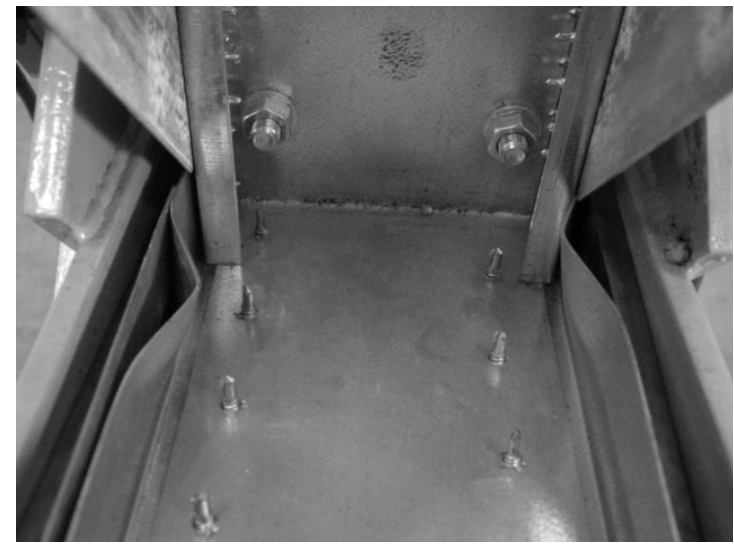

Fig. 48. Local buckling in WOG UC2.

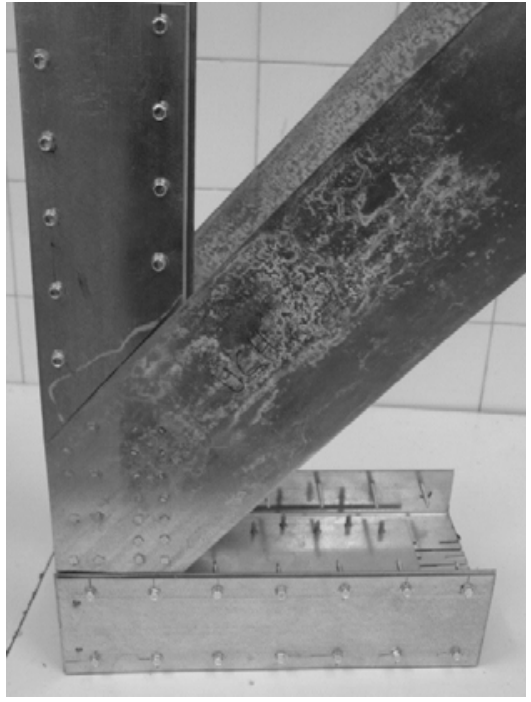

Fig. 49. Reinforced WOG UC4 joint.

Table 9. Results of tests and calculations on UC joints.

$\mathrm{P}_{\mathrm{ut}}$ : experimental ultimate load, $\mathrm{A}_{\mathrm{gt}}$ : measured gross cross-sectional area, $\mathrm{f}_{\mathrm{yt}}$ : measured yield stress $\mathrm{r}_{\mathrm{f}}$ : force ductility ratio, $\mathrm{P}_{\mathrm{Rd}}$ : calculated ultimate load.

\begin{tabular}{|c|c|c|c|c|c|}
\hline Connection & $\begin{array}{l}\text { Failure } \\
\text { mode }\end{array}$ & $\begin{array}{l}P_{u t} \\
(N)\end{array}$ & $\begin{array}{l}A_{g t} \cdot f_{y t} \\
(N)\end{array}$ & $r_{f}$ & $\begin{array}{l}P_{\mathrm{Rd}} \\
(\mathrm{N})\end{array}$ \\
\hline WOG UC1-A & NSF & 123350 & 114807 & 1.07 & 127269 \\
\hline WOG UC1-B & NSF & 122160 & 111256 & 1.10 & 124618 \\
\hline WOG UC2 & LB & 55040 & 74220 & 0.74 & 81620 \\
\hline WOG UC3-A & LB & 72600 & 113548 & 0.64 & 127172 \\
\hline WOG UC3-B & LB & 109520 & 114455 & 0.96 & 127366 \\
\hline WOG UC4 & LB & 118950 & 176223 & 0.67 & 196682 \\
\hline WOG UC5 & LB & 98906 & 114807 & 0.86 & 128595 \\
\hline WG UC1 & NSF & 46570 & 46097 & 1.01 & 45358 \\
\hline WG UC2 & NSF & 46950 & 45622 & 1.03 & 45836 \\
\hline WG UC3 & LB & 61710 & 58587 & 1.05 & 64906 \\
\hline WG UC4 & LB & 69540 & 59614 & 1.17 & 66108 \\
\hline
\end{tabular}

At this point, it was decided to reinforce the studs and the tracks of the WOG UC joints still not tested. Additional plates and profiles were attached to the original specimens. See in Fig. 49 the reinforced UC4 joint (the specimen shown in Fig. 43 is also a reinforced joint).

In spite of the reinforcements, the failure of the WOG UC3-B and UC4 joints kept on affecting the studs. These joints collapsed due to local buckling of the web of the inner stud (Fig. 50). The ultimate loads, however, improved. They were higher than the ones obtained for the unreinforced joints (Table 9).

The reinforced WOG UC1 joint was the only one that gave the required net section failure at the design ultimate load (Fig. 51).

In relation to WG UC specimens, it should be said that there were two groups of joints that behaved slightly different. On the one hand, the WG UC joints with narrow straps $(\mathrm{sw}=65 \mathrm{~mm}$ ) worked very well. Net section failure of the straps 
was the mode of failure observed in the two tests performed on these specimens (Fig. 52). On the other hand, the upper corners with wide straps $(\mathrm{sw}=100 \mathrm{~mm})$, did not collapse in the way they were expected to. In spite of the reinforcements, the strength of stud and track was not high enough. Joints failed due to local buckling of the compressed members (Fig. 53). However, the experimental ultimate loads that resulted from tests were close to the NSF calculated strengths of the straps $\left(P_{r d}\right.$ values in Table 9$)$. For this reason, it is believed that the straps were about to fail when buckling of the members occurred.

Apart from the local buckling phenomena and the net section failure, tilting occurred in some of the WG joints. On the contrary, significant bearing was not observed in any specimen. In this sense, the behaviour of corner joints is rather different from the behaviour of strap and gusset joints.

The F-d curves of WOG UC specimens are similar to the F-d curves of WOG LC joints. They show initial linear behaviour and gradual yielding (Fig. 54). On the contrary, the behaviour of WG UC joints is more similar to the behaviour of the strap and gusset joints of the previous phases, showing elastic, yielding, hardening and failure branches (Fig. 55). For this reason, it may be said that the

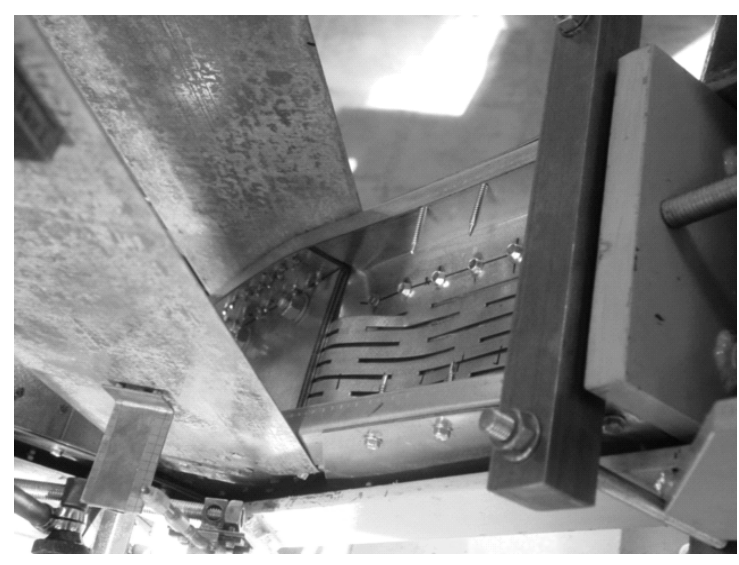

Fig. 50. Local buckling in WOG UC3-B .

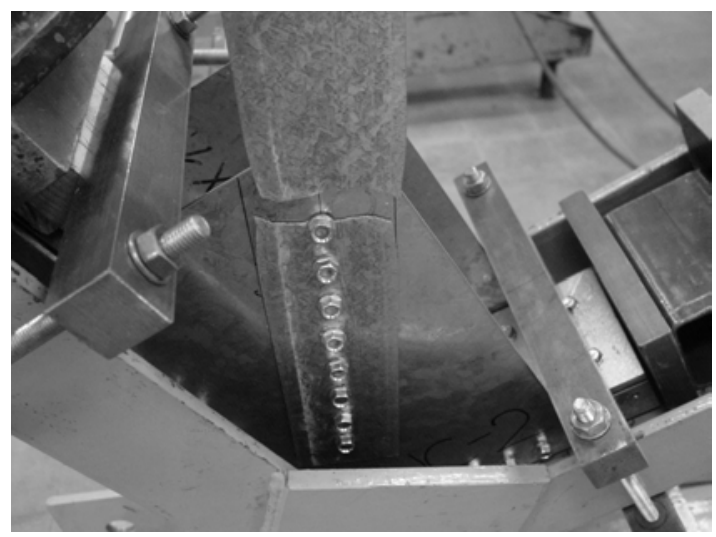

Fig. 52. Net section failure in WG UC1.

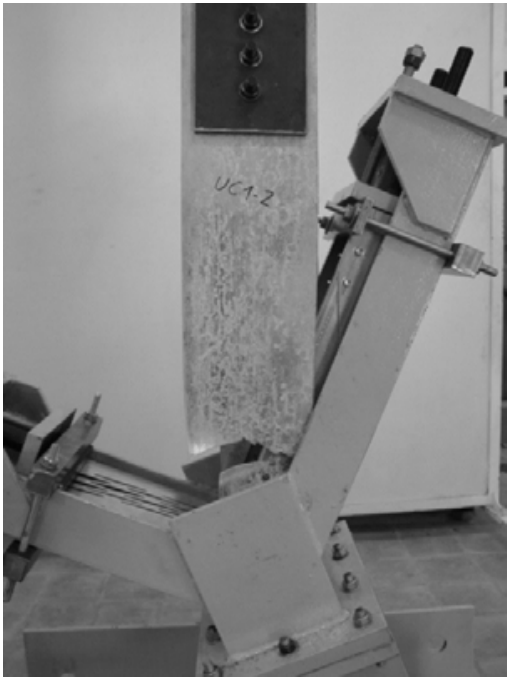

Fig. 51. Net section failure in WOG UC1-B.

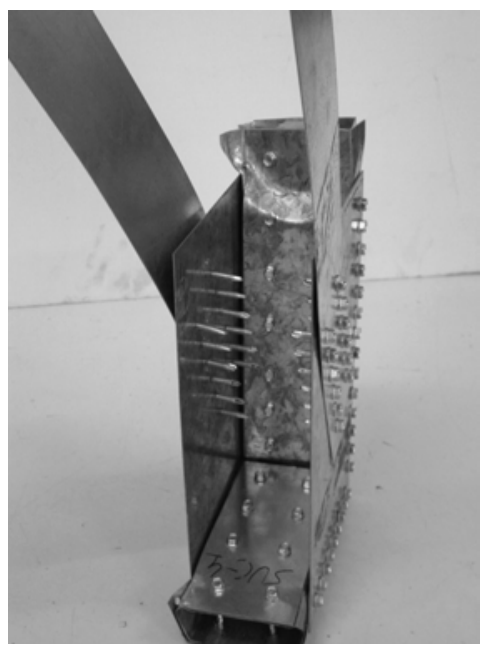

Fig. 53. Local buckling in WG UC3. 


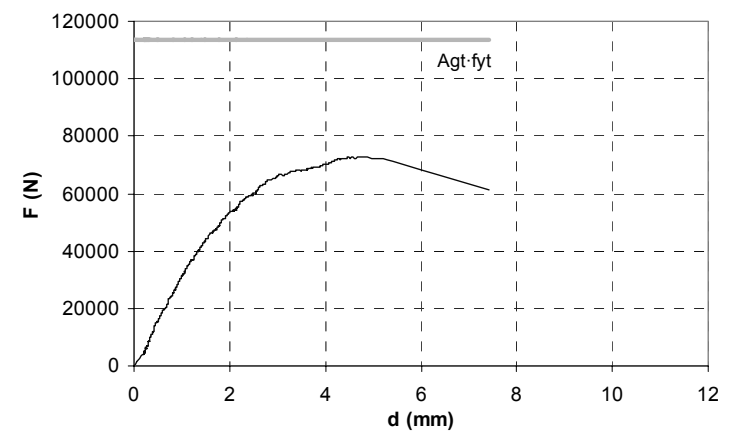

Fig. 54. F-d curve specimen WOG UC3-A.

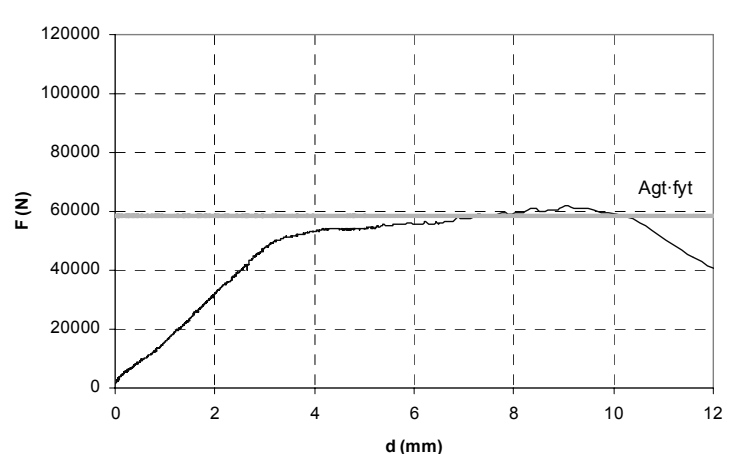

Fig. 55. Local buckling in WG UC3.

use of gussets results in good behaviour of upper joints. WG joints have the good ductile performance of the NSF strap and gusset connections shown in sections 2 and 3.

The seismic suitability of the NSF connections is again verified by means of the force ductility ratio $r_{f}$ included in Table 9 . It is noted that the two last LB failures shown in this table, which have a $r_{f}$ ratio higher than 1 , occurred when the joints were about to collapse in the NSF mode.

\section{Tests on $\mathrm{x}$-braced shear frames}

\subsection{Test specimens}

Tests are performed on two identical shear frames whose height is about four times shorter than the height of a conventional frame (Fig. 56). This reduced model is used because it will allow to record the hysteretic response of the $x$ braced frames avoiding any problem related to premature buckling of studs.

The main components of the shear panels are two tracks, two studs and four diagonal straps. Tracks and studs are composed of U100 and C100 profiles. The diagonal bracings are two straps of $65 \mathrm{~mm}$ in width and $0.8 \mathrm{~mm}$ in thickness. Diagonals are connected to studs and tracks through $210 \times 140 \mathrm{~mm}$ gusset plates whose thickness is $1.5 \mathrm{~mm} . \phi 6.3 \mathrm{~mm}$ self-drilling screws are used to connect all the components of the frame.

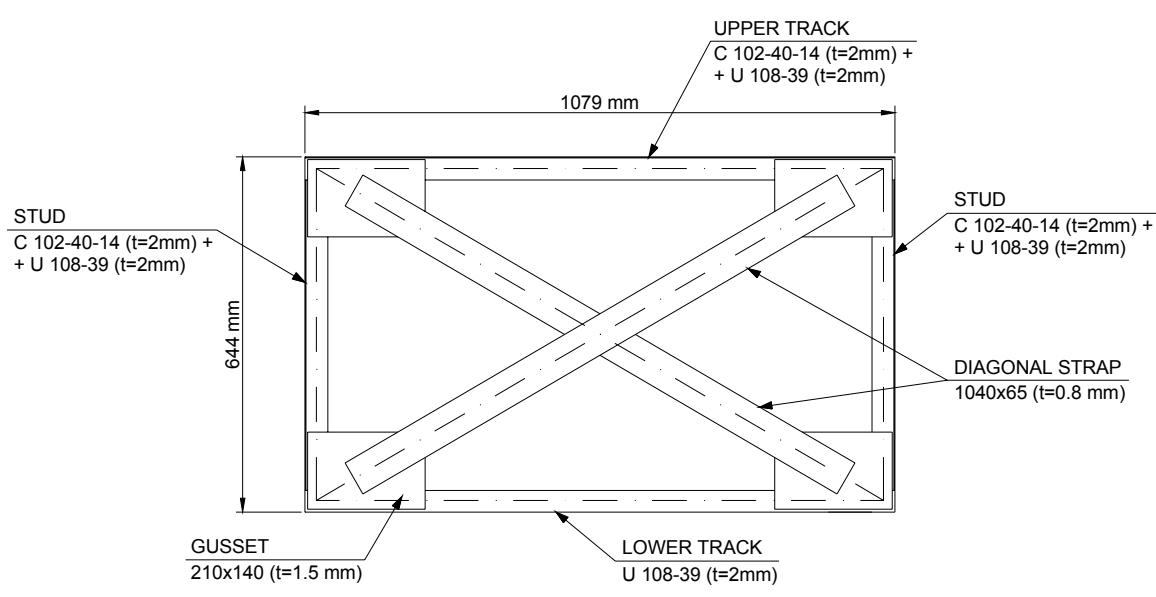

Fig. 56. Shear frame tested. 
It should be pointed out that, apart from the issue of the size of studs discussed above, some other decisions are taken to make sure that the dissipative yielding of the straps occurs before failure:

1. Diagonal straps are thin and narrow. On the contrary, the cold-formed profiles chosen for tracks and studs have high load bearing capacity.

2. The steel grade of the diagonal straps is lower than the steel grade of the other members of the frame. Furthermore, a steel of low grade and ductile is used in straps, thus giving them more dissipation capacity.

3. Only one row of screws is used to connect the straps to the gussets. This results in high net cross section area, which also increases the dissipation capacity of the strap (see [8]). The row contains nine screws, so that the strength of the connection is governed by the net section failure mode, and the bearing failure is avoided (the design calculations were performed according to Eurocode 3 Part 1-3 [17], applying its partial safety factors).

4. Anchor bolt connections without eccentricity are used, so that all the dissipative yielding takes place in the straps and premature failure of the corner joints is avoided.

\subsection{Test procedure}

Firstly, the steel mechanical properties of diagonal straps are measured by means of tensile tests. The experimental values obtained result to be significantly different from the nominal values. The yield stress is lower: $f_{y}=250$ $\mathrm{N} / \mathrm{mm}^{2}$ vs. $f_{y t}=224 \mathrm{~N} / \mathrm{mm}^{2}$; while the ultimate load is higher: $f_{\mathrm{u}}=330 \mathrm{~N} / \mathrm{mm}^{2}$ vs. $\mathrm{f}_{\mathrm{ut}}=365 \mathrm{~N} / \mathrm{mm}^{2}$. This will provoke an earlier yielding of diagonal straps and it will also increase their ductility (the $f_{u} / f_{y}$ ratio is higher than planned).

Figs. 57 and 58 show the test setup. A $100 \mathrm{kN}$ hydraulic cylinder is used to apply a horizontal force. This force is measured by means of a load cell placed at the end of the cylinder. Two measurements of displacement are also taken: the displacement of the cylinder and the displacement of the upper track of the specimen, which is measured by means of an external displacement transducer. All the measured data is stored in a computer.

Tests are displacement-controlled. The displacement input is shown in Fig. 59. There are five loading cycles with an increasing value of displacement

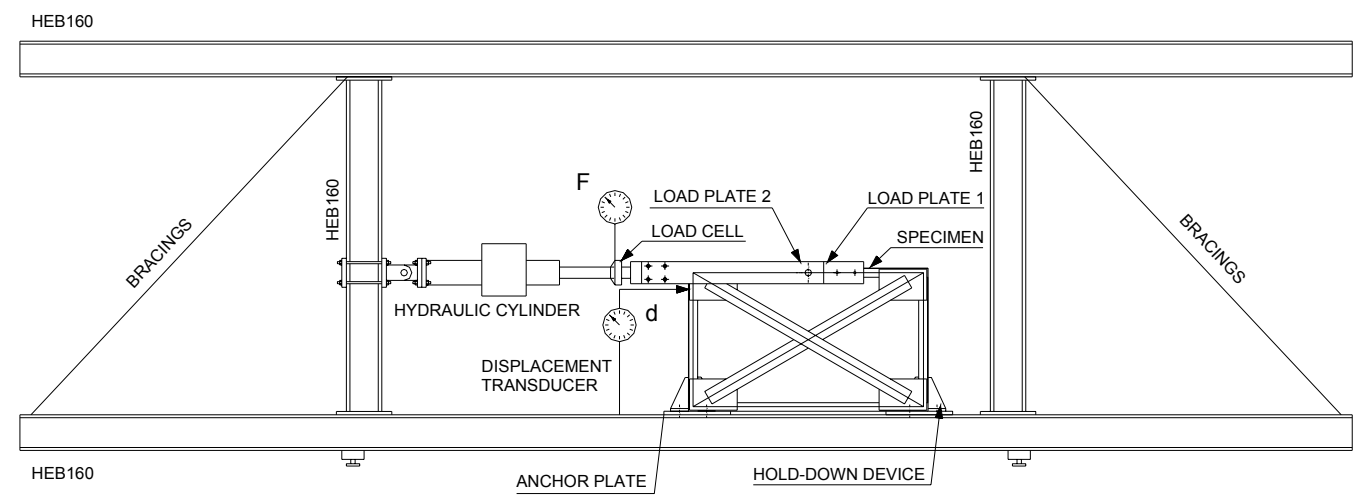

Fig. 57. Test setup. 


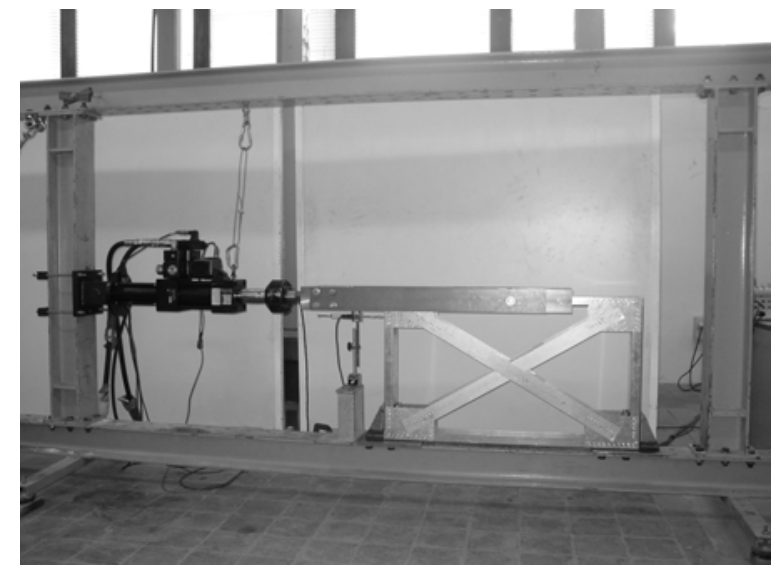

Fig. 58. Frame ready to be tested.

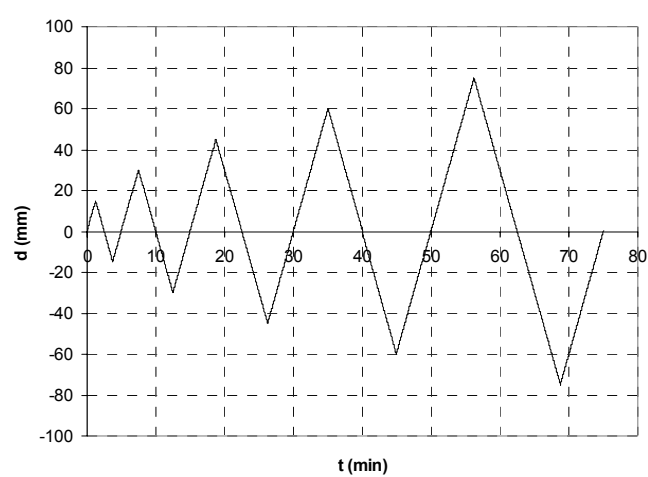

Fig. 59. Displacement input.

amplitude that ranges from $\pm 15 \mathrm{~mm}$ to $\pm 75 \mathrm{~mm}$. The displacement law is chosen so that yielding of the diagonal straps occurs from the first cycle of the test. The maximum displacement is limited to the maximum allowable displacement amplitude of the hydraulic cylinder, $160 \mathrm{~mm}$.

The loading rate is constant for all the cycles: $0.2 \mathrm{~mm} / \mathrm{s}$. Measured data, i.e., force and displacement, are read at the same rate.

\subsection{Test results}

Two main subjects are discussed in the present section: the behaviour of the frames observed during the cyclic tests and the force-displacement curves obtained.

Just from the beginning, the compressed straps buckle. It is flexural buckling in two or three half sine waves. There is also yielding of the straps in the first cycle, as it was planned. This can be seen in Fig. 60, which shows the plastic deformation of the diagonal straps at the end of the first cycle.

Other phenomena are observed as the displacement amplitudes increase. From cycle 2 on, local buckling of the upper corner gussets can be seen (Fig. 61).

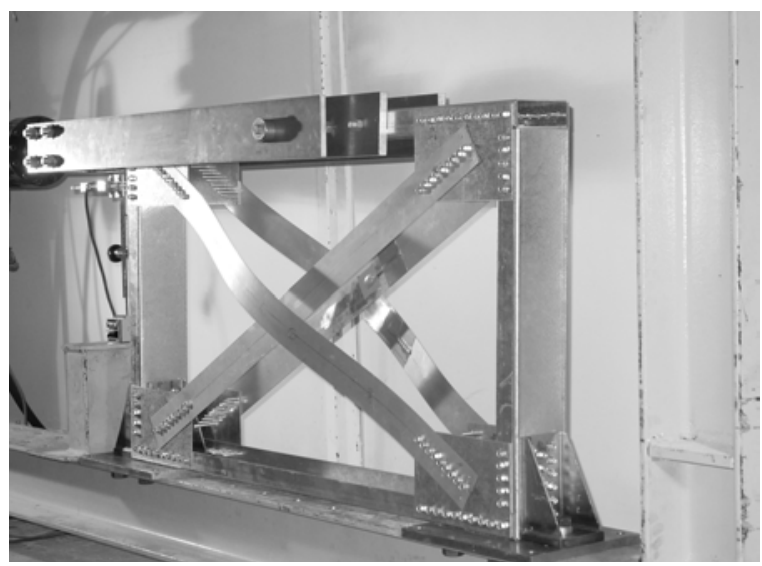

Fig. 60. Yielded straps after the first complete cycle.

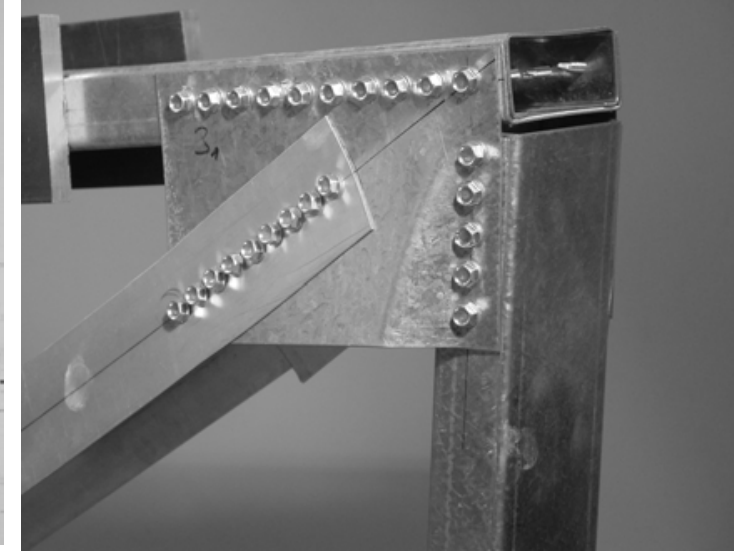

Fig. 61. Local buckling of the upper corner gusset. 


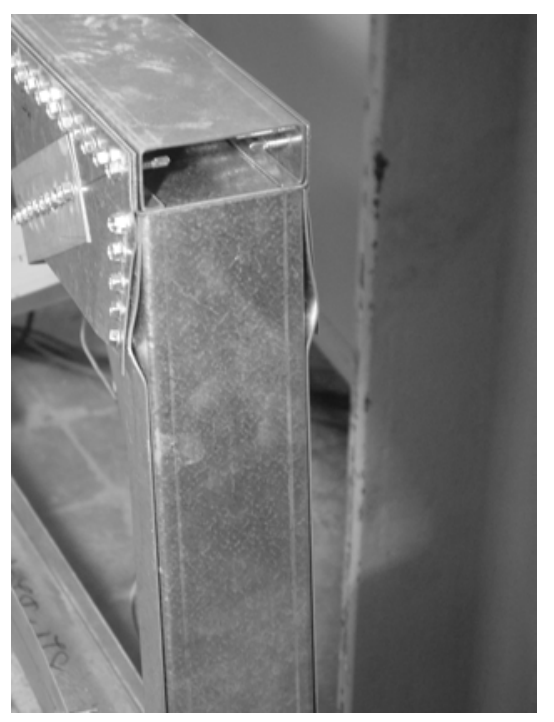

Fig. 62. Local buckling of the stud flanges.

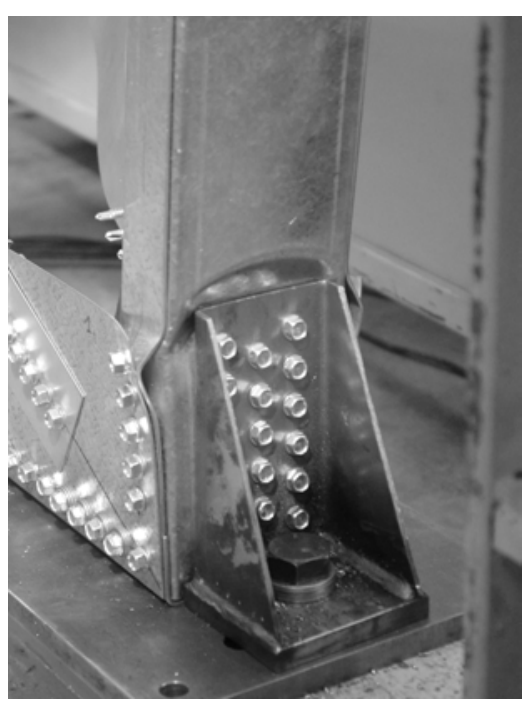

Fig. 63. Local damage in lower corner joints.

The horizontal movement of the upper track provokes a decrease of the angle between track and stud in one of the upper corners, and an increase of the same angle in the other one. Where the angle decreases, the gusset is subjected to compression and, as a consequence, it buckles. This local instability is not observed in lower corners, because the hold-down plates constrain the track-stud angle.

In the other corner, where the angle increases, local buckling of the stud flanges occurs (Fig. 62). The track-stud joint is a semi-rigid connection and, consequently, the horizontal displacement of the track causes a bending moment to appear in the stud. This bending moment provokes the local buckling of the compressed parts of the stud flanges.

In a similar way, the studs of the lower corner joints undergo local buckling. These joints are even more rigid because they are reinforced by means of the hold-down plates. In this case, the bending moment provokes local buckling of flanges and webs (Fig. 63).

In view of the results obtained, it is believed that the shear frames tested show satisfactory performance, because all the failure modes observed in the previous phases of the experimental campaign have been avoided. Furthermore, a correct development of the dissipative action of the straps has taken place, as can be seen Fig. 64 and 65. However, it should also be pointed out that local damage occurred in joints as a consequence of their semi-rigid nature. This local plastification in studs and gussets is common and difficult to avoid in this type of structures. For the frames tested, it specially affects lower corners, where the stiffening effect of the hold-down plates is high. In real $x-$ braced frames, whose studs are about four times higher than the studs of the frames tested, this local plastification in joints will not be so relevant at so small horizontal displacements. 


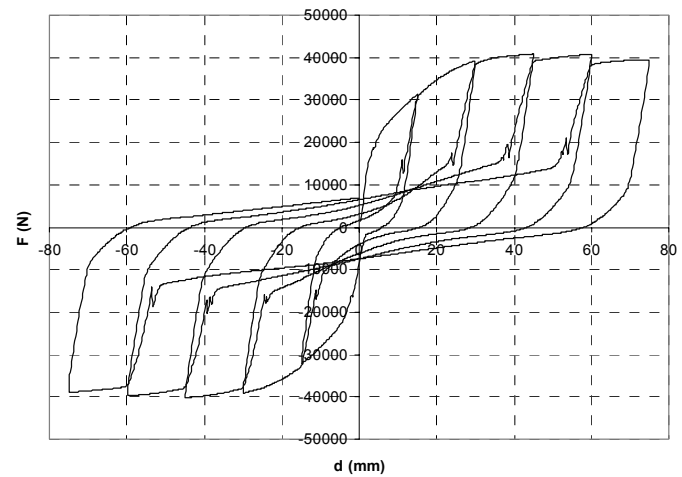

Fig. 64. F-d curve of specimen 1.

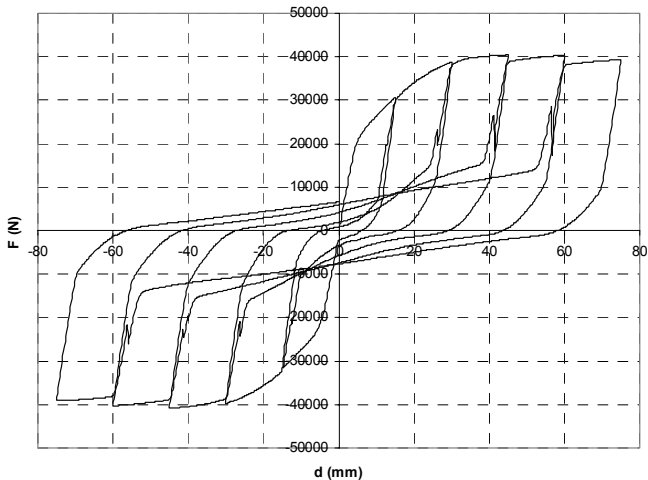

Fig. 65. F-d curve of specimen 2

Neither significant tilting nor bearing are observed during the tests. In this sense, the behaviour of the corner joints is similar to the behaviour of the strap joints failing NSF that connected two plates of different thickness investigated in the first phase of the experimental campaign [7]. As there is not hole elongation, the slipping phenomenon does not occur.

The force-displacement curves obtained in the tests (Fig. 64 and 65) show pinching and slackness, as it is usual for $x$-braced frames $[5,13,18]$. In the first loading cycle, a small initial linear branch is observed that, subsequently, transforms into progressive yielding. Afterwards, the unloading takes place showing a linear branch whose slope is similar to the linear loading branch. A symmetric buckle is repeated for the negative displacements. In fact, the behaviour of the frame is symmetric all through the test.

The second loading positive branch has a slightly lower slope. There is a small stiffness degradation as the number of cycles increase, which affects loading branches in a higher degree than unloading branches.

There is also a small strength degradation. From the third cycle on maximum loads decrease slowly. It should be pointed out that the maximum force applied is somewhat higher than the load predicted in design calculations. This is due to the fact that corner joints are actually semi-rigid.

Semi-rigid joints also result in pinching load levels different than zero. During the first steps of the loading part of a cycle, load has to be applied despite the diagonal straps are yielded and buckled. This load is necessary to make the joints move until the straps are tensioned again.

Finally, it should be noted that a small, but sudden, fall in the forcedisplacement curves is observed in the loading branches of every cycle. This fall is caused by a small dynamic phenomenon that occurs when gussets go from their buckled configuration to the tensioned one.

\section{Conclusions and design recommendations}

The goal of this closing section is to offer some practical recommendations for the design and modelling of joints under seismic conditions. For each relevant 
aspect (failure modes, material properties, etc.) a few concluding remarks are first given and then translated into recommendations.

The aim is to give the complete final set of recommendations that result from the whole investigation carried out. For this reason, some of the conclusions presented in Part 1 and $2[7,8]$ are also included in this section, although they have not been fully derived in the present paper.

\section{Failure modes}

The failure mode of joints is a key issue in the seismic design of lightweight steel structures. Many different phenomena have been observed in the tests: bearing, tilting, pull-out, pull-through, net section failure, shear failure of the connection device, punching, tearing, local buckling,... The preferred mode for seismic design is net section failure, because i) it is the most ductile and ii) for $x$-braced frames, it is the only mode that allows the dissipative action of diagonal straps to take place. For this reason,

R1. All joints (strap-strap, strap-gusset, upper and lower corners) must be designed to fail in the net section mode; any type of bearing failure of the joint and shear failure of the connection device must be especially avoided.

To allow the dissipative action of diagonal straps or other bracing systems (such as steel plates), it is also important to avoid the failure of other parts of the shear wall (besides the joints). That is,

R2. Failure due to local bending and subsequent punching of tracks in lower corners should be avoided. In these sense, it is recommended to reduce as much as possible the eccentricity between lower corner joints and anchor bolts, and to use suitable hold-down plates.

R3. Instability of tracks and studs (local, distortional or global buckling) should be avoided.

\section{Material properties}

The steel grade is another key issue in seismic design, because the yield strength and the ultimate strength control the plastification and failure of each member. Due to this,

$R 4$. It is crucial that the frame is built with the steel grade specified in the design phase. The use of a steel of higher grade (i.e. higher mechanical properties) than specified may result in non-adequate seismic response.

R5. For $x$-braced frames, the steel grade of the diagonal straps should be lower than the steel grade of the rest of the frame (studs, tracks and gussets)

\section{Connection devices}

Screws are better than bolts and other connection devices from the seismic point of view. The main reason is that their diameter is smaller and, consequently, there is more net section area available. For this reason,

R6. Self-drilling screws should be the preferred means of connection in seismic design. 


\section{Screwed connections}

Two main failure modes are encountered in screwed connections: $\mathrm{T}+\mathrm{B}+\mathrm{PO}$ (tilting, bearing and pull-out) and T+NSF (tilting and net section failure). As discussed above, NSF is preferable, because it allows the dissipative action of the bracing system. Consequently,

R7. Bearing of screwed connections should be avoided (for instance, by placing enough screws in the joint, and by connecting the straps to thicker gussets).

\section{Bolted connections}

Bolts are less adequate than screws for the seismic design of joints. In fact, only bolt connections with washers are suitable for seismic design, but in a lower degree than screw connections. If, for some specific reason, bolts are chosen (not recommended), then take into account that

R8. Acceptable seismic performance of bolted connections may be achieved by i) using only one row of bolts; ii) using washers; iii) drilling the minimum feasible hole; iv) choosing the steel with the largest ratio of ultimate to yield strength; v) widening the straps in the perforated areas, if manufacturing constraints of $x$ braced frames allow.

\section{$X$-braced frames}

The last phase of the joint testing campaign shows that properly designed $\mathrm{x}$ braced frames are a very effective means of dissipating seismic energy in a controlled manner:

$R 9$. In the design of $x$-braced frames, follow the recommendations above to ensure that the dissipative action of diagonal straps can take place.

In the tests of the $x$-braced frames a significant local plastification was observed at the lower part of the studs, provoked by the stiffening effect of hold-down plates. For this reason,

R10. Hold-down plates should be designed in such a way that lower corner joints are not excessively stiffened.

\section{Design methods}

The Eurocode 3 Part 1.3 formulas for the calculation of the net section strength of screwed and bolted joints give acceptable results. On the contrary, the formulas for the bearing mode of failure may result in predictions of the ultimate load that give too much overstrength. Due to this,

R11. (For code developers) Bearing formulas in Eurocode 3 Part 1.3 should be improved.

\section{Numerical modelling}

A detailed finite element model, for instance, is a very useful tool for the design of a corner joint. The global seismic response of a shear wall, on the other hand, may be modelled more efficiently by means of other approaches. For example, good results are obtained with the single-degree-of-freedom hysteretic 
model developed in this project and presented in [3]. In view of the results of the experimental campaign, the hysteretic model developed includes the following features:

1. Initial linear behaviour.

2. Gradual yielding.

3. No stiffness degradation.

4. No load degradation.

5. Symmetric behaviour.

6. Pinching.

7. Slackness

8. Stiffness of the frame without straps (semi-rigid nature of corner joints).

9. No hardening.

10. No slipping.

\section{References}

[1] De Matteis G, Landolfo R. Structural behaviour of sandwich panel shear walls: An experimental analysis. Materials and Structures 1999; 32: 331-341.

[2] prEN 1998-1. Eurocode 8: Design of structures for earthquake resistance. Part 1. General rules, seismic acions and rules for buildings. CEN European Committee for standardization. Brussels, 2002 (Draft).

[3] Pastor N. Numerical Modelling of the Seismic Behaviour of Cold-Formed Steel Structures. Phd. Thesis. Universitat Politècnica de Catalunya (UPC) 2006.

[4] De Matteis G, Landolfo R. Mechanical fasteners for cladding sandwich panels: Interpretative models for shear behaviour. Thin-Walled Structures 1999; 35: 61-79.

[5] Fülöp LA, Dubina D. Performance of wall-stud cold-formed shear panels under monotonic and cyclic loading. Part I: Experimental research. ThinWalled Structures 2004, 42(2): 321-228.

[6] Fülöp LA, Dubina D. Design Criteria for Seam and Sheeting-to-Framing Connections of Cold-Formed Steel Shear Panels. Journal of Structural Engineering 2006; 132(4): 582-590.

[7] Casafont M, Arnedo A, Roure F, Rodríguez-Ferran A. Experimental testing of joints for seismic design of lightweight structures. Part 1: Screwed joints in straps. Thin-Walled Structures 2006, 44: 197-210.

[8] Casafont M, Arnedo A, Roure F, Rodríguez-Ferran A. Experimental testing of joints for seismic design of lightweight structures. Part 2: Bolted joints in straps. Thin-Walled Structures 2006, 44: 677-691.

[9] Kawai Y, Kanno R, Uno N, Sakumoto Y. Seismic Resistance and Design of Steel-Framed Houses. Nippon Steel Technical Report 1999, 79: 6-16. 
[10] Liew YL, Duffield CF, Gad EF. The influence of plasterboard clad walls on the structural behaviour of low rise residential buildings. Electronic Journal of Structural Enginnering 2002; 1.

[11] Gad EF, Duffield CF, Hutchinson GL, Mansell DS, Stark G. Lateral performance of cold-formed steel-framed domestic structures. Engineering Structures 1999; 21: 83-95.

[12] Tian YS, Wang J, Lu TJ. Racking strength and stiffness of cold-formed steel wall frames. Journal of Constructional Steel Research 2004; 60:10691093.

[13] Pastor N, Rodríguez-Ferran A. Hysteretic modelling of $\mathrm{x}$-braced shear walls. Thin-Walled Structures 2005; 43(10): 1567-1588.

[14] Gad EF, Chandler AM, Duffield CF, Stark G. Lateral Behaviour of Plasterboard-Clad Residential Steel Frames. Journal of Structural Engineering 1999; 125(1): 32-39.

[15] De Matteis G, Landolfo R. Modelling of lightweight sandwich shear diaphragms for dynamic analyses. Journal of Constructional Steel Research 2000; 53: 33-61.

[16] Morro T, Experimental campaign of shear connections used in light-gauge steel structures, Final Degree Thesis, Universitat Politècnica de Catalunya; 2004 (in Catalan).

[17] Eurocode 3: Design of steel structures - Part 1-3: General rules supplementary rules for cold-formed members and sheeting. CEN European Committee for Standardisation, Brussels, 2004 (Draft).

[18] Berman JW, Oguz CC, Bruneau M. Comparing hysteretic behavior of lightgauge steel plate shear walls and braced frames. Engineering Structures 2005; 27: 475-485. 